\title{
A redox-flow battery with an alloxazine-based organic electrolyte
}

\section{Citation}

Lin, Kaixiang, Rafael Gómez-Bombarelli, Eugene S. Beh, Liuchuan Tong, Qing Chen, Alvaro Valle, Alán Aspuru-Guzik, Michael J. Aziz, and Roy G. Gordon. 2016. "A Redox-Flow Battery with an Alloxazine-Based Organic Electrolyte." Nature Energy 1 (9) (July 18): 16102. doi:10.1038/ nenergy.2016.102.

\section{Published Version}

10.1038/nenergy.2016.102

\section{Permanent link}

http://nrs.harvard.edu/urn-3:HUL.InstRepos:33439113

\section{Terms of Use}

This article was downloaded from Harvard University's DASH repository, and is made available under the terms and conditions applicable to Open Access Policy Articles, as set forth at http:// nrs.harvard.edu/urn-3:HUL.InstRepos:dash.current.terms-of-use\#OAP

\section{Share Your Story}

The Harvard community has made this article openly available.

Please share how this access benefits you. Submit a story.

\section{Accessibility}


A redox flow battery with an alloxazine-based organic electrolyte

Kaixiang Lin ${ }^{1}$, Rafael Gómez-Bombarelli ${ }^{1}$, Eugene S. Beh ${ }^{1,2}$, Liuchuan Tong ${ }^{1}$, Qing Chen $^{2}$, Alvaro Valle ${ }^{3}$, Alán Aspuru-Guzik ${ }^{1}$, Roy G. Gordon ${ }^{1,2^{*}}$, Michael J. Aziz ${ }^{2^{*}}$

${ }^{1}$ Department of Chemistry and Chemical Biology, Harvard University, 12 Oxford Street, Cambridge, Massachusetts 02138, USA

${ }^{2}$ Harvard John A. Paulson School of Engineering and Applied Sciences, 29 Oxford Street, Cambridge, Massachusetts 02138, USA

${ }^{3}$ Harvard College, Cambridge, Massachusetts 02138, USA *E-mail: RGG (gordon@chemistry.harvard.edu) and MJA (aziz@seas.harvard.edu) from variable sources, such as solar and wind. Recently, redox-active organic molecules in aqueous RFBs have drawn substantial attention due to their rapid kinetics and low membrane crossover rates. Drawing inspiration from nature, here we report a high-performance aqueous RFB utilizing an organic redox compound, alloxazine, which is a tautomer of vitamin $B_{2}$ 's isoalloxazine backbone. It can be synthesized in high yield at room temperature by single-step coupling of inexpensive o-phenylenediamine derivatives and alloxan. The highly alkaline-soluble alloxazine 7/8-carboxylic acid (ACA) produces a RFB exhibiting open-circuit voltage approaching 1.2 volts and current efficiency and capacity retention exceeding $99.7 \%$ and $99.98 \%$ per cycle, respectively. Theoretical studies indicate that structural modification of alloxazine with electron donating groups should allow further 
23 increases in battery voltage. As an aza-aromatic molecule that undergoes reversible

24 redox cycling in aqueous electrolyte, alloxazine represents a class of radical-free

25 redox-active organics for use in large-scale energy storage.

Improved methods for storing electrical energy from intermittent renewable

27 sources are needed to support the rapid deployment of photovoltaic (PV) and wind

28 power. $^{1-3}$ A promising approach for safe and cost-effective stationary energy storage uses

29 redox flow batteries (RFBs), in which the energy is stored in fluids held outside the

30 power conversion electrochemical cell. ${ }^{4,5}$ This permits the independent engineering of

31 energy (electrolyte volume and/or concentration) and power (cell area) capacities and

32 enables the attainment of the high energy-to-power ratios (i.e. long discharge durations at

33 rated power) necessary to deliver energy from PV and wind when it is needed. Since the

34 invention of RFBs in the 1970s, the development efforts for its electrolyte materials - the

35 core component of RFBs - have concentrated on single metal ions such as vanadium,

36 iron and chromium, where the battery voltages are fixed by the reduction potentials of

37 these ions, and their solubilities and stabilities are governed by the $\mathrm{pH}$ and composition

38 of the supporting electrolyte. ${ }^{6,7}$ However, their development has been impeded by one or

39 more shortcomings such as high electrolyte corrosivity, toxicity, cost, membrane cross-

40 over rate, or sluggish reaction kinetics.

41 Contrary to the limited numbers of metal ions suitable for RFBs, organic

42 molecules display high chemical diversity, allowing optimization of electrolyte properties

43 such as higher solubility (by adding solubilizing groups), higher voltage (by varying the

44 electron donating properties of functional groups), and lower membrane cross-over rate

45 (by tuning the molecular size or net charge on the molecules). Recently, researchers have 
46 demonstrated RFBs of much improved performance by rational design of organic-based

47 electrolyte materials (summarized in Table 1). ${ }^{8-13}$ For instance, Huskinson et al. utilized a

48 sulfonic-acid functionalized 9,10-anthraquinone, which showed fast kinetics and high

49 solubility in a supporting electrolyte of sulfuric acid; by pairing it up with cheap

50 bromine/hydrobromic acid, the team showed approximately a three-fold reduction of the

51 potential cost of electrolyte materials, compared with state-of-art all-vanadium RFBs. ${ }^{8,9}$

52 The toxicity and corrosivity of bromine, however, limit its use to industrial and utility

53 settings. By switching from acidic to alkaline supporting electrolyte, Lin et al.

54 demonstrated a less corrosive and non-toxic RFB using hydroxylated 9,10-anthraquinone

55 and a food additive, ferrocyanide, targeted for residential and commercial usage. ${ }^{10}$ To

56 reduce membrane cost while maintaining a low membrane crossover rate, Janoschka et

57 al. prepared polymeric methyl viologen and (2,2,6,6-tetramethylpiperidin-1-yl)oxidanyl

58 (TEMPO) which showed almost no sign of membrane crossover when cheap dialysis

59 membranes were used in place of expensive cation-exchange membranes. ${ }^{11}$ Despite these

60 great advances, each system still has potential for further improvement, such as replacing

61 toxic halogen species with high-performance organic molecules, increasing the ion

62 conductivity and energy density of alkaline systems, and reducing the high electrolyte

63 viscosity associated with the dissolution of polymers at practical concentrations. To

64 accelerate the development of organic-based RFBs, more compounds with useful redox

65 potential, high solubility, and ease of synthesis are highly desired. Previous aqueous

66 organic-based RFBs have utilized only three types of stable redox-active species: 1)

67 quinones, 2) TEMPO and 3) methyl viologen, as shown in Table 1. To date, tailored

68 improvements have been proven possible only in quinone systems. 
Gaining inspiration from naturally occurring flavin cofactors, here we report a

70 novel alloxazine-based aqueous organic RFB. Alloxazines can be synthesized via a

71 simple and high-yielding coupling reaction between $o$-phenylenediamine derivatives and

72 alloxan in acetic acid and boric acid at room temperature and atmospheric pressure

73 (Table 2). ${ }^{14-16}$ Functionalization of alloxazine with a carboxylic acid group renders the

74 alloxazine molecule highly soluble in alkaline solution - up to $2 \mathrm{M}$ in pH $14 \mathrm{KOH}$, which

75 corresponds to a charge density of $108 \mathrm{Ah} / \mathrm{L}$. By pairing it up with ferri/ferrocyanide as

76 the positive electrolyte, we built a high-performance RFB characterized by an open-

77 circuit voltage approaching $1.2 \mathrm{~V}$ and current efficiency and capacity retention exceeding

$78 \quad 99.7 \%$ and 99.98\% per cycle, respectively. Enabled by a high-throughput computational

79 study, a relationship between different alloxazine functional groups and their effects on

80 reduction potential was established and exploited to guide the design of future alloxazine-

81 based electrolyte materials. For instance, by replacing the carboxylic acid group with

82 another alkaline-soluble hydroxyl group, the battery voltage can be further raised by

83 almost $10 \%$.

84 Rational Design of Electrolyte Material

85 Designing an appropriate organic molecule as electrolyte material starts from

86 identifying redox-active cores followed by functionalization of the core structure to

87 achieve a practical reduction potential and solubility. We observed that riboflavin 5'

88 phosphate (FMN), a highly water-soluble compound derived from vitamin $\mathrm{B}_{2}$, undergoes

89 two-electron reduction via a flavin semiquinone radical intermediate on its isoalloxazine

90 backbone (Supplementary Fig. 1). ${ }^{17,18}$ In alkaline solution, it exhibited high reversibility

91 and a low reduction potential of $-0.53 \mathrm{~V}$ vs. SHE (Fig. 1a). Further exploration of its 
92 isoalloxazine motif led to the discovery that lumichrome, an alloxazine derivative that

93 differs from isoalloxazine by its diazabutadiene double bond configuration, exhibited a

94 much lower reduction potential of $-0.70 \mathrm{~V}$ vs. SHE (Fig. 1b). Alloxazine had previously

95 been studied in the solid state as an anode material for non-aqueous lithium and sodium

96 ion batteries. ${ }^{19}$ However, the low solubility of alloxazine in a wide range of solvents

97 presents a challenge for solution-phase applications. To increase its solubility in aqueous

98 solution, we functionalized the alloxazine core with an alkali-soluble carboxylic acid

99 group by coupling o-phenylenediamine-4-carboxylic acid (a.k.a. 3,4-diaminobenzoic acid)

100 with alloxan to afford an isomeric mixture of alloxazine 7/8-carboxylic acid (ACA) in

101 almost 100\% yield (Supplementary Fig. 2). The reduction potential of ACA from CV

102 measurement is $-0.62 \mathrm{~V}$ vs. SHE (Fig. 1c). The larger separation between its oxidation

103 and reduction peaks than those of FMN and lumichrome is likely due to slower kinetics.

104 From our rotating disk electrode (RDE) measurement, the reduction rate constant was

105 measured to be $1.2 \pm 0.2 \times 10^{-5} \mathrm{~cm} \mathrm{~s}^{-1}$ (Supplementary Fig. 3). Nevertheless, this value is

106 still an order of magnitude higher than that of the slower side of all-vanadium RFBs. ${ }^{6}$

Besides the large shift in reduction potential moving from isoalloxazine to

108 alloxazine, we also observed a significant increase in chemical stability in alkaline

109 conditions. Whereas cyclic voltammetry (CV) measurement of 0.5 M FMN in an alkaline

110 solution revealed an almost 70\% decrease in reduction signal within 2 weeks, an ACA

111 solution at the same concentration showed almost no sign of degradation (Supplementary

112 Fig. 4). Quantification of ACA stability was achieved by proton nuclear magnetic

113 resonance $\left({ }^{1} \mathrm{H}\right.$ NMR) analysis of a $0.5 \mathrm{M}$ solution of ACA maintained at $\mathrm{pH} 14$ over the

114 course of six weeks. The decomposition of ACA, assuming first-order kinetics $\left(\mathrm{R}^{2}=\right.$ 
115 0.991), had a rate constant of $1.39 \times 10^{-3}$ day $^{-1}$, equivalent to a solution half-life of 500

116 days (Supplementary Fig. 5). This combination of lower reduction potential (-0.62 V vs.

$117-0.53 \mathrm{~V}$ ) and higher chemical stability (500 days vs. 10 days half-life of FMN at pH 14),

118 made ACA a much better candidate for an electrolyte material.

119 Electrochemical Full-cell Study

To demonstrate ACA in a full cell, we paired ACA with ferri/ferrocyanide (Fig.

121 1c and d). The battery was assembled using 0.5 M ACA (1.5 mmol) as the negative

122 electrolyte and $0.4 \mathrm{M}$ ferrocyanide $(4.5 \mathrm{mmol})+40 \mathrm{mM}$ ferricyanide $(0.46 \mathrm{mmol})$ as the

123 positive electrolyte. Both solutions were adjusted to $\mathrm{pH} 14$ by $\mathrm{KOH}$. Excess quantities of

124 ferrocyanide and ferricyanide were used to ensure the negative terminal remained the

125 capacity-limiting side for the purpose of evaluating its electrochemical stability during

126 cycling. The resulting alkaline aqueous RFB showed an open-circuit voltage (OCV)

127 approaching $1.2 \mathrm{~V}$. The OCV versus state-of-charge (SOC) monotonically increased from

$12810 \%$ to $90 \%$ SOC (Fig 2a). Polarization studies conducted at room temperature showed a

129 peak power density of $0.35 \mathrm{~W} \mathrm{~cm}^{-2}$ at a current density of $0.58 \mathrm{~A} \mathrm{~cm}^{-2}$. The linearity of

130 the polarization curves allows us to derive a polarization area-specific resistance (ASR),

131 which is $1.03 \Omega \mathrm{cm}^{2}$ at $50 \%$ SOC. About $70 \%$ of this cell ASR is contributed by the

132 membrane (Supplementary Fig. 6), similar to our previous observation. ${ }^{10}$ Note that ACA

133 redox kinetics does not show up as a significant kinetic overvoltage loss (i.e. a non-

134 linearity at the low overvoltage region) in the polarization curve, likely owing to the large

135 surface area provided by the porous carbon electrodes. The electrochemical stability of

136 ACA was evaluated based on an extended charge-discharge study over 400 cycles (Fig.

137 2c). The current efficiency exceeded $99.7 \%$ at $0.1 \mathrm{~A} \mathrm{~cm}^{-2}$, which is indicative of 
138 negligible side reactions during cell cycling and a low crossover rate through the

139 membrane. The round-trip energy efficiency in this cycling experiment averaged around

$14063 \%$. The battery exhibited a remarkably high capacity retention rate of more than $91 \%$

141 over 400 cycles, or a capacity loss rate of $0.023 \%$ per cycle. To further analyze capacity

142 retention, we compared the total charge from the cell before and after cycling using

143 chronoamperometry to charge and discharge the cell at constant voltage (Supplementary

144 Fig. 7). From this result, the measured capacity retention from 400 cycles was 95\%, i.e.

145 the loss rate was $0.013 \%$ per cycle. We believe the discrepancy between this

146 measurement and the capacity retention observed during constant-current cycling was

147 due to an increase of system resistance (which we infer from decreasing energy

148 efficiency with cycle number); this effect moved the charging and discharging curves

149 closer to the cutoff voltages, resulting in less complete charging and discharging with

150 increasing cycle count (Supplementary Fig. 8). We expect further cell development,

151 including variations in $\mathrm{pH}$, membrane and sealing method, to lead to further improvement

152 of capacity retention. By increasing the concentration of ACA to $1 \mathrm{M}$, we increased the

153 electrolyte charge density by almost two-fold (Supplementary Fig. 9a). Together with

154 adjusted cell compression and higher ACA concentration, we were able to improve

155 round-trip energy efficiency to $74 \%$, while retaining the same level of current efficiency

156 (99.7\%) and capacity retention per cycle (99.95\%) (Supplementary Fig. 9b).

\section{Theoretical Modeling and Screening}

One useful feature of organic electrolyte materials is the ability to optimize their 159 properties through chemical modification, a process that can be accelerated by virtual

160 testing with computational methods. ${ }^{8,20}$ We assayed the chemical landscape around the 
161 alloxazine backbone by computing the properties of derivatives bearing one to four

162 copies of each of seven functional groups. Selected examples of alloxazine derivatives

163 subjected to the theoretical modeling are shown in Table 3 (a complete table of the rest of

164 the studied alloxazine derivatives can be found in supplementary table 1).

Figure 3 shows the variation in predicted standard reduction potential $\left(E^{0}\right)$ within 166 the alloxazine class. The additive effect of electron donating and electron withdrawing 167 groups is observed as they lower and raise the reduction potential, respectively, across a 168 range of $400 \mathrm{mV}$. Hydroxyl, methyl and methoxy substituents afford the largest increases 169 in cell potential. We prepared 7/8-hydroxyalloxazine and 7,8-dimethylalloxazine via the 170 aforementioned $o$-phenylenediamine-alloxan coupling chemistry (Table 2,

171 Supplementary Fig. 10 and 11). CV of these two compounds showed values below $172-0.73 \mathrm{~V}(\sim 110 \mathrm{mV}$ lower than ACA), potentially raising the battery voltage by another $17310 \%$ (Fig 3c and d).

174 In addition to tuning its reduction potential, modification of alloxazine with 175 appropriate functional groups could also improve its chemical stability. Alloxazines 176 undergo ring-opening reaction in aqueous solvent via addition of water to the amidic 177 carbonyls followed by continuing hydrolysis to redox-inactive species (Supplementary

178 Fig. 12). ${ }^{21}$ Increases in $\mathrm{pH}$ catalyze the hydrolysis process, as observed in the FMN 179 stability study and informed by literature. ${ }^{22,23}$ Nevertheless, the low $\mathrm{p} K_{\mathrm{a}}$ values at the 180 amide nitrogen (8.4 and 11.4 for lumichrome ${ }^{24}$ ) result in the accumulation of two 181 negative charges in the imidic conjugate system at high $\mathrm{pH}$ values; this process ultimately 182 hinders the hydrolysis reaction by lowering the electrophilicity of the carbonyl groups. ${ }^{25}$ 183 Since the redox center and the center of electrophilic reactivity are separate in alloxazines, 
184 design strategies are available to decrease chemical reactivity, such as tuning the

185 electrophilicity of alloxazines via different functional groups. We evaluated all the

186 screened alloxazines based on their predicted equilibrium constant, $K_{\text {hyd }}$, for the

187 reversible hydration of the carbonyl groups (Fig. 3b), with lower value of $K_{\text {hyd }}$

188 corresponding to less electrophilic carbonyls. We found that the same electron-donating

189 groups that contribute toward the desired reduction potential values also have a protecting

190 effect against hydrolysis, as is the case with amides in general (i.e. hydrolysis rate of

191 amides in basic medium has a linear dependence in $\left.K_{\text {hyd }}\right) .{ }^{26}$ For instance, hydroxyl

192 derivatives lower $K_{\text {hyd }}$ by as much as two orders of magnitude, thereby shifting the

193 equilibrium toward the redox-active “de-hydrated” form.

\section{Conclusions}

By drawing inspiration from vitamin $\mathrm{B}_{2}$, we introduced a novel family of organic molecules for RFB applications. The alloxazine redox-center exhibits sufficiently high

197 electrochemical and chemical stability, and sufficiently low reduction potential, to be 198 exploited as a negative electrolyte material in an alkaline RFB. Synthesis of a

199 functionalized alloxazine redox-active center was carried out via a very simple coupling 200 chemistry utilizing only o-phenylenediamine derivatives, alloxan, acetic acid and boric 201 acid, without employing high temperature or pressure. We paired alloxazine 7/8202 carboxylic acid with ferri/ferrocyanide to demonstrate a high-performance alloxazine203 powered RFB. The current efficiency exceeded 99.7\% while its capacity retention over 204400 charge-discharge cycles was shown to be $~ 95 \%$ cumulatively, or $99.98 \%$ per cycle. 205 With a better understanding of the alloxazine system enabled by theoretical modeling, we 206 have designed and characterized another two alloxazine-derived molecules promising 
207 almost 10\% further increase in battery voltage. The introduction of aza-aromatic redox-

208 active species opens up a new direction in designing organic electrolyte and delivers a

209 promising pathway to accelerate development of aqueous organic RFBs. 
211 Chemical synthesis and characterization 3,4-diaminophenol was purchased from Aurum Pharmatech and

212 used as received. All other chemicals were purchased from Sigma Aldrich and used as receieved.

213 Alloxazines were prepared following previously reported methods. ${ }^{14-16}$ In general, o-phenylenediamine (5

$214 \mathrm{mmol})$ was added to $45 \mathrm{~mL}$ acetic acid followed by alloxan $(5.5 \mathrm{mmol})$ and boric acid $(5.5 \mathrm{mmol})$. The

215 reaction mixture was stirred at room temperature and atmospheric pressure under nitrogen. The reaction

216 times for various alloxazine derivatives are summarized in Table 2. After reaction, the product was

217 collected by vacuum filtration, washed with acetic acid, water, and diethyl ether, and air dried overnight.

218 The products were analyzed by ${ }^{1} \mathrm{H}$ NMR and used for chemical and electrochemical measurement without

219 further purification. ${ }^{1} \mathrm{H}$ NMR spectra were recorded using Varian INOVA 500 (500 MHz) NMR

220 spectrometers at $23^{\circ} \mathrm{C}$. Proton chemical shifts are expressed in parts per million (ppm, $\delta$ scale) and are

221 referenced to residual protium in the NMR solvent $\left(\mathrm{D}_{2} \mathrm{O}, \delta 4.80 \mathrm{ppm}\right.$ and $\left.\left(\mathrm{CD}_{3}\right)_{2} \mathrm{SO}, \delta 2.50 \mathrm{ppm}\right)$. The

222 isomeric ratio between major and minor product during the preparation of ACA and 7/8-hydroxyalloxazine

223 was estimated based on their peak integration ratio (highlighted in Supplementary Fig. 2 and 10).

224 Stability test by ${ }^{1}$ H NMR In a nitrogen-filled glove bag, a sample of ACA (0.5 M) was dissolved in a

225 solution of $40 \%$ wt. KOD in $\mathrm{D}_{2} \mathrm{O}$ (used as received from Sigma-Aldrich) which was then adjusted to pH 14

226 with the appropriate amount of $\mathrm{D}_{2} \mathrm{O}$. The sample was sealed inside a J. Young tube and analyzed by ${ }^{1} \mathrm{H}$

227 NMR. Analyses of the same sample were performed after 14, 21, 28, and 42 days. Between analyses, the J.

228 Young tube was returned to the glove bag where it was kept in the dark. The proportion of ACA that had

229 decomposed was determined by integrating the peaks at $6.48 \mathrm{ppm}$ and comparing it to the peaks at 6.60

230 ppm and $6.86 \mathrm{ppm}$, which come from the starting material. From this data, the rate constant of ACA

231 decomposition was calculated assuming first-order kinetics (Supplementary Fig. 4).

232 Solubility measurement by UV-Vis spectroscopy Saturated solution of ACA was prepared by addition of

233 ACA to a pH 14 solution until precipitate formed. $\mathrm{KOH}$ was added if necessary to maintain the solution $\mathrm{pH}$.

234 Aliquots of the supernatant were diluted with a $\mathrm{pH} 14 \mathrm{KOH}$ solution and its absorbance measured using

235 UV-Vis spectrophotometry (Ocean Optics FLAME-S-UV-VIS; cuvettes are made out of polystyrene with a 
236 path length of $1 \mathrm{~cm}$ ). Readings were interpolated based on a standard calibration curve prepared by 237 measuring the absorbance of known concentrations of ACA (Supplementary Fig. 13).

238 Electrochemical analysis Three-electrode cyclic voltammetry tests (CV) were performed using a glassy

239 carbon working electrode, a $\mathrm{Ag} / \mathrm{AgCl}$ reference electrode (pre-soaked in $3 \mathrm{M} \mathrm{NaCl}$ solution) and a

240 platinum counter electrode. For the full cell measurements, cell hardware from Fuel Cell Tech.

241 (Albuquerque, NM) was used to assemble a zero-gap flow cell configuration, similar to previous reports. ${ }^{27}$

242 POCO graphite flow plates with serpentine flow fields were used for both sides. A $5 \mathrm{~cm}^{2}$ geometric surface

243 area electrode comprised a stack of two or three sheets of Sigracet SGL 10AA porous carbon paper,

244 pretreated by baking in air at $400{ }^{\circ} \mathrm{C}$ for $24 \mathrm{~h}$. A sheet of Nafion 212 membrane, pretreated in DI water

245 overnight, served as the ion-selective membrane. The rest of the space between the plates was gasketed by

246 either Kalrez or Teflon sheets. The electrolytes were fed into the cell through PFA tubing, at a rate of 60

$247 \mathrm{~mL} / \mathrm{min}$ controlled by Cole-Parmer Masterflex L/S peristaltic pumps. All electrochemical tests were

248 performed using a Gamry Reference 3000 potentiostat.

249 Rotating disk electrode (RDE) measurement RDE experiments were conducted using a BASi RDE 250 (RDE-2) instrument equipped with a glassy carbon working electrode, a Ag/AgCl reference electrode (pre251 soaked in $3 \mathrm{M} \mathrm{NaCl}$ solution) and a platinum counter electrode. The electrode was rotated at a specific 252 speed while the voltage was linearly swept from $-0.70 \mathrm{~V}$ to $-1.20 \mathrm{~V}$ versus $\mathrm{Ag} / \mathrm{AgCl}$. The reduction rate 253 constant of ACA was calculated from the Tafel equation using the following parameters: $n=2$; Faraday's 254 constant $F=96,485 \mathrm{C} \mathrm{mol}^{-1}$; electrode area $A=0.0707 \mathrm{~cm}^{2}$, ACA concentration $C=2 \times 10^{-6} \mathrm{~mol} \mathrm{~cm}^{-3}$; 255 kinematic viscosity $v=0.01 \mathrm{~cm}^{2} \mathrm{~s}^{-1}$ (Supplementary Fig. 3). The experiment was performed three times.

256 Electrolyte preparation For SOC, polarization and 400-cycle charge-discharge studies, the positive 257 electrolyte was prepared by dissolving ferrocyanide ( $1.9 \mathrm{~g}, 4.5 \mathrm{mmol})$ and ferricyanide ( $0.15 \mathrm{~g}, 0.46 \mathrm{mmol})$ 258 in $1 \mathrm{M} \mathrm{KOH}$ solution $\left(11.25 \mathrm{~mL}\right.$ ) to afford 0.4 molar electron concentration and 2.7 molar $\mathrm{K}^{+}$ion solution 259 (11 Ah/L charge density). The negative electrolyte was prepared by dissolving ACA (0.39 g, $1.5 \mathrm{mmol})$ in $2602.5 \mathrm{M} \mathrm{KOH}$ solution (adjusted to final volume of $3 \mathrm{~mL}$ ) to afford 1 molar electron concentration and 2 261 molar $\mathrm{K}^{+}$ion solution (27 Ah/L charge density). For high concentration ACA cycling experiment, the 262 positive electrolyte was prepared by dissolving ferrocyanide ( $3.8 \mathrm{~g}, 9 \mathrm{mmol})$ and ferricyanide $(0.3 \mathrm{~g}, 0.91$ 
mmol) in $1 \mathrm{M} \mathrm{KOH}$ solution (22.5 mL) to afford 0.4 molar electron concentration and 2.7 molar $\mathrm{K}^{+}$ion

264 solution (11 Ah/L charge density). The negative electrolyte was prepared by dissolving ACA (0.78 g, 3

$265 \mathrm{mmol}$ ) in $4 \mathrm{M} \mathrm{KOH}$ solution (adjusted to final volume of $3 \mathrm{~mL}$ ) to afford 2 molar electron concentration

266 and 4 molar $\mathrm{K}^{+}$ion solution (54 Ah/L charge density).

\section{Computational studies}

268 Libraries considered. We have analyzed all the possible substitutions for each functional group on all the 269 possible sites of the alloxazine core. The functional groups assessed are carboxylic acid, fluoro, hydroxyl, 270 methoxy, methyl, phosphonic acid and sulfonic acid. Substitution on the alloxazine amide nitrogens were 271 not considered as they destabilize alloxazines under alkaline condition. A total of 105 backbones were

272 analyzed. Initial conformations were generated that used a random-distance matrix approach at the mmff94

273 level of theory. Geometries were further refined using DFT and single-point calculations were performed

274 using larger basis sets and solvent corrections. The following methods were tested for obtaining

275 equilibrium geometries and total energies: PM7, PM7 + implicit COSMO solvation, PBE/6-31G*,

276 B3LYP/6-31G*. In addition, single point calculations were performed at both B3LYP/6-311+G(d,p) and

277 B3LYP/6-311+G(d,p) combined with CPCM implicit solvation. Their relative performance is compared in

278 the supplementary information file. For both target properties we obtained the smallest error using

279 B3LYP/6-311+G(d,p) CPCM. Reduction potentials were predicted from the energy difference between the 280 reduced and oxidized forms of alloxazines, assuming a two-electron two-proton process. Prior to

281 conducting predictions, we assessed the performance of various quantum chemical methods to calculate the 282 two-proton two-electron redox potential of alloxazine and isoalloxazine rings at $\mathrm{pH}=7.4 \mathrm{using}$ a

283 calibration scheme analogous to the one reported for quinones. The calibration dataset was composed of 23

284 experimentally-reported molecules, with $E_{\mathrm{pH}=7}^{0}$ ranging between $-380 \mathrm{meV}$ and $-80 \mathrm{meV}$ versus RHE. ${ }^{28}$

285 Our results suggest that quick semiempirical methods and gas-phase DFT calculations afford results with

286 mean errors around $20 \mathrm{meV}$. DFT calculations in implicit solvent with a larger basis set reduce the average

287 error to under $10 \mathrm{meV}$. The performance of various methods is reported in Supplementary Table 2. We then 288 corrected $E^{0}$ values to $\mathrm{pH}=14.0$. Pourbaix diagrams were estimated combining experimental and predicted $289 \mathrm{p} K_{\mathrm{a}}$ values $\left(\mathrm{p} K_{\mathrm{a}}^{\mathrm{ox}}=8.3,11.4 ; \mathrm{p} K_{\mathrm{a}}^{\text {red }}=6.7,10.0\right)$. The shift from $\mathrm{pH}=7.4$ to $\mathrm{pH}=14.0$ for alloxazines is 
290 thus estimated at $-320 \mathrm{meV}$. To calculate hydration equilibrium, we used an experimental dataset from the 291 literature including aldehydes, ketones, esters and amides and mapped theoretical reaction energies at $0 \mathrm{~K}$ 292 to experimentally-determined hydration equilibrium constants in water. ${ }^{29}$. The calibration dataset was 293 composed of 41 experimentally-reported molecules, with $\log K_{\text {hyd }}$ ranging between -15 and 5 . DFT 294 calculations in implicit solvent result in mean errors close to 1 log unit. The performance of various 295 methods is reported in Supplementary Table 2. 


\section{References}

297 1. Dunn, B., Kamath, H. \& Tarascon, J.-M. Electrical Energy Storage for the Grid: A 298 Battery of Choices. Science 334, 928-935 (2011).

299 2. Nguyen, T. \& Savinell, R. F. Flow Batteries. Electrochem. Soc. Interface 19, 54-56 $300 \quad$ (2010).

301 3. Yang, Z. et al. Electrochemical Energy Storage for Green Grid. Chem. Rev. 111, $302 \quad 3577-3613(2011)$.

303 4. Biello, D. Solar Wars. Sci. Am. 311, 66-71 (2014).

304 5. Skyllas-Kazacos, M., Chakrabarti, M. H., Hajimolana, S. A., Mjalli, F. S. \& Saleem, 305 M. Progress in Flow Battery Research and Development. J. Electrochem. Soc. 158, 306 R55-R79 (2011).

307 6. Weber, A. Z. et al. Redox flow batteries: a review. Journal of Applied 308 Electrochemistry 41, 1137-1164 (2011).

309 7. Perry, M. L. \& Weber, A. Z. Advanced Redox-Flow Batteries: A Perspective. J. $310 \quad$ Electrochem. Soc. 163, A5064-A5067 (2016).

311 8. Huskinson, B. et al. A metal-free organic-inorganic aqueous flow battery. Nature 505, 312 195-198 (2014).

313 9. Huskinson, B., Marshak, M. P., Gerhardt, M. R. \& Aziz, M. J. Cycling of a Quinone314 Bromide Flow Battery for Large-Scale Electrochemical Energy Storage. ECS Trans. $315 \quad 61,27-30(2014)$.

316 10. Lin, K. et al. Alkaline quinone flow battery. Science 349, 1529-1532 (2015).

317 11. Janoschka, T. et al. An aqueous, polymer-based redox-flow battery using non318 corrosive, safe, and low-cost materials. Nature 527, 78-81 (2015). 
12. Schubert, U. S. et al. Polymer/Zinc Hybrid-Flow Battery Using Block Copolymer

320 Micelles featuring a TEMPO Corona as Catholyte. Polym Chem 28, 2238-2243 (2016).

321 13. Liu, T., Wei, X., Nie, Z., Sprenkle, V. \& Wang, W. A Total Organic Aqueous Redox

322 Flow Battery Employing a Low Cost and Sustainable Methyl Viologen Anolyte and 4-

323 HO-TEMPO Catholyte. Adv. Energy Mater. 6, 1501449 (2015).

324 14. Chen, S., Hossain, M. S. \& Foss, F. W. Organocatalytic Dakin Oxidation by

325 Nucleophilic Flavin Catalysts. Org. Lett. 14, 2806-2809 (2012).

326 15. Gonzalo, G. de, Smit, C., Jin, J., Minnaard, A. J. \& Fraaije, M. W. Turning a

327 riboflavin-binding protein into a self-sufficient monooxygenase by cofactor redesign.

328 Chem. Commun. 47, 11050-11052 (2011).

329 16. Lindén, A. A., Johansson, M., Hermanns, N. \& Bäckvall, J.-E. Efficient and Selective

330 Sulfoxidation by Hydrogen Peroxide, Using a Recyclable Flavin-[BMIm]PF6

331 Catalytic System. J. Org. Chem. 71, 3849-3853 (2006).

332 17. Hasford, J. J. \& Rizzo, C. J. Linear Free Energy Substituent Effect on Flavin Redox

333 Chemistry. J. Am. Chem. Soc. 120, 2251-2255 (1998).

334 18. Müller, F. in Radicals in Biochemistry 71-107 (Springer, 1983).

335 19. Hong, J. et al. Biologically inspired pteridine redox centres for rechargeable batteries.

$336 \quad$ Nat. Commun. 5, (2014).

337 20. Er, S., Suh, C., Marshak, M. P. \& Aspuru-Guzik, A. Computational design of

338 molecules for an all-quinone redox flow battery. Chem Sci 6, 885-893 (2015).

339 21. Koziol, J. \& Metzler, D. E. Formation and Possible Structure of Covalent Hydrates of

$340 \quad$ Alloxazines. Z. Für Naturforschung B 27, 1027-1029 (2014). 
341 22. Surrey, A. R. \& Nachod, F. C. Alkaline Hydrolysis of Riboflavin. J. Am. Chem. Soc.

$342 \quad 73,2336-2338$ (1951).

343 23. Ahmad, I., Rapson, H. D. C., Heelis, P. F. \& Phillips, G. O. Alkaline hydrolysis of

344 7,8-dimethyl-10-(formylmethyl)isoalloxazine. A kinetic study. J. Org. Chem. 45, 731-

$345733(1980)$.

346 24. Prukała, D. et al. Acid-Base Equilibriums of Lumichrome and its 1-Methyl, 3-Methyl, 347 and 1,3-Dimethyl Derivatives. J. Phys. Chem. A 116, 7474-7490 (2012).

348 25. Koziol, J., Tyrakowska, B. \& Müller, F. The structure of covalent hydrates of

349 alloxazines. A reinvestigation. Helv. Chim. Acta 64, 1812-1817 (1981).

350 26. O’Connor, C. Acidic and basic amide hydrolysis. Q. Rev. Chem. Soc. 24, 553-564

351 (1970).

352 27. Liu, Q. H. et al. High Performance Vanadium Redox Flow Batteries with Optimized

353 Electrode Configuration and Membrane Selection. J. Electrochem. Soc. 159, A1246-

354 A1252 (2012).

355 28. Li, X.-L. \& Fu, Y. Theoretical study of reduction potentials of substituted flavins. J.

356 Mol. Struct. THEOCHEM 856, 112-118 (2008).

357 29. Gómez-Bombarelli, R., González-Pérez, M., Pérez-Prior, M. T., Calle, E. \& Casado, J.

358 Computational Calculation of Equilibrium Constants: Addition to Carbonyl

359 Compounds. J. Phys. Chem. A 113, 11423-11428 (2009).

360

361 


\section{Acknowledgements}

363 This work was funded by the U.S. DOE ARPA-E award \# DE-AR0000348, NSF \# NSF-

364 CBET-1509041, the Massachusetts Clean Energy Technology Center and the Harvard

365 John A. Paulson School of Engineering and Applied Sciences. RGB and A A-G

366 acknowledge the use of the Harvard FAS Odyssey Cluster and support from FAS

367 Research Computing. We thank Chenxi Qian for designing the Figure 1d scheme.

\section{Author Contributions}

369 K.L., R.G.G. and M.J.A. formulated the project. K.L., and L.T. synthesized the

370 compounds. K.L., E.S.B. and L.T. collected and analyzed the NMR data. K.L., Q.C.,

371 E.S.B. and A.V. collected and analyzed the electrochemical data. K.L. and A.V.

372 measured solubility. R.G.B. and A.A.-G. performed theoretical analysis. K.L., R.G.G.

373 and M.J.A. wrote the paper, and all authors contributed to revising the paper.

\section{Additional Information}

375 Supplementary information is available online. Reprints and permissions information is 376 available online at www.nature.com/reprints. Correspondence and requests for materials

377 should be addressed to R.G.G and M.J.A.

\section{Competing interests}

379 The authors declare no competing financial interests. 
a

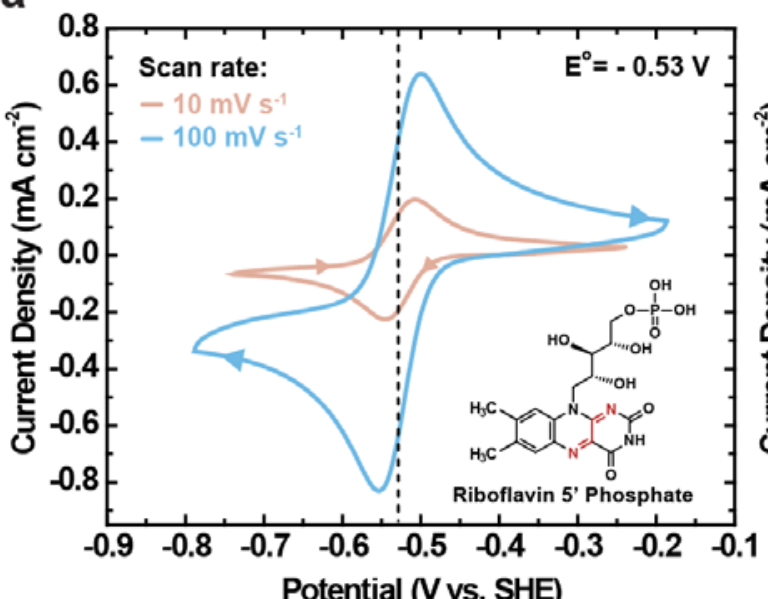

C

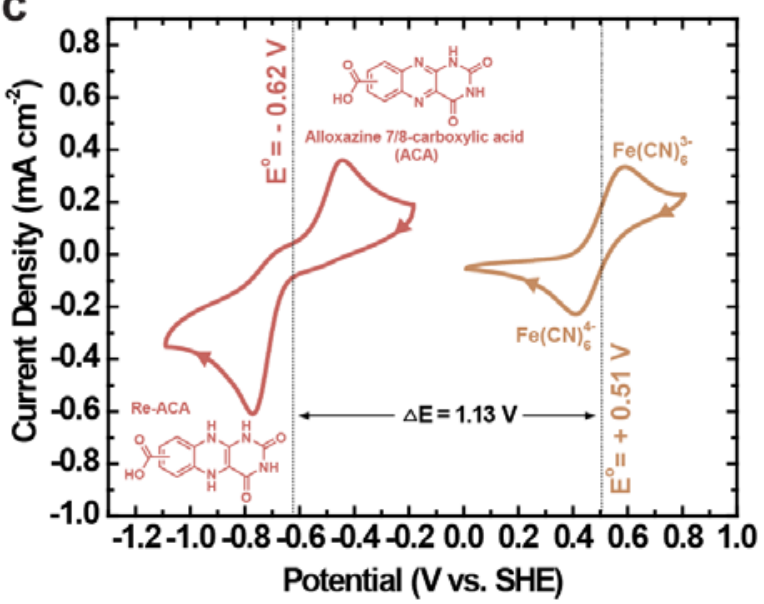

b

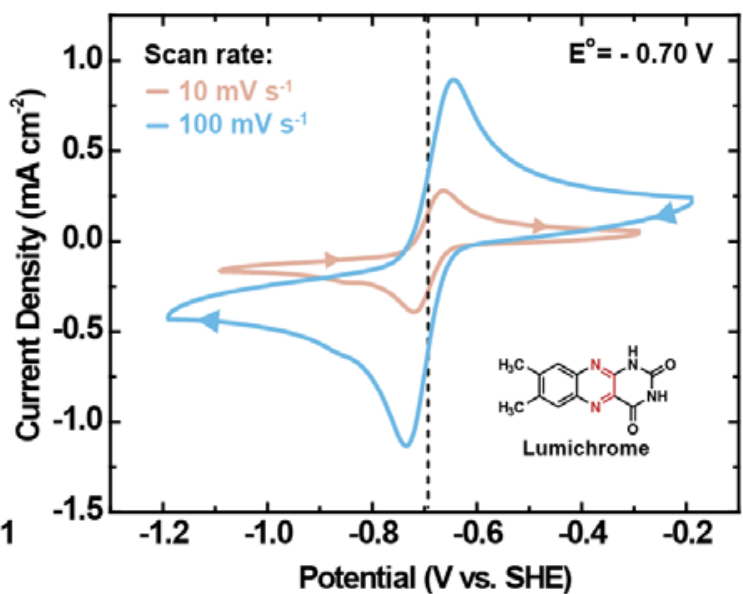

d

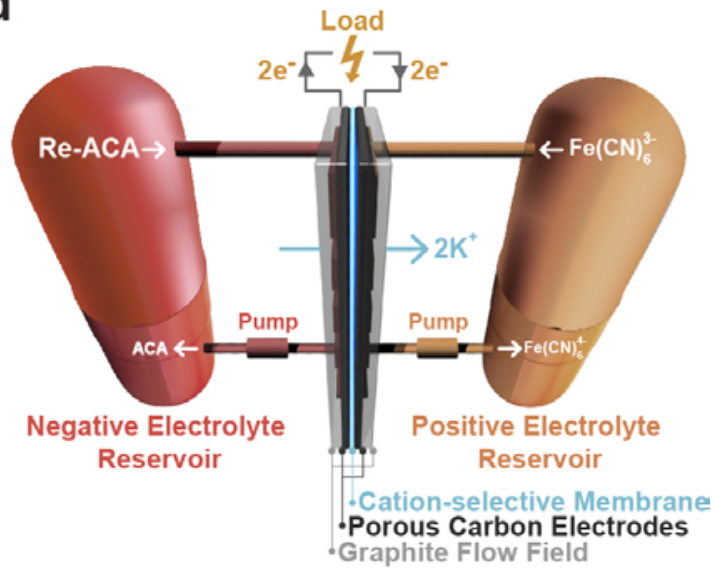

Figure 1 | Cyclic Voltammogram and Cell Schematic. a and b, Molecular structures and cyclic voltammogram of $2 \mathrm{mM}$ riboflavin 5' phosphate (FMN) and lumichrome, respectively, scanned at $10 \mathrm{mV} / \mathrm{s}$ and $100 \mathrm{mV} / \mathrm{s}$ on glassy carbon electrode. c, Cyclic voltammogram of $2 \mathrm{mM}$ alloxazine 7/8-carboxylic acid (ACA) (red curve) and ferrocyanide (gold curve) scanned at $100 \mathrm{mV} / \mathrm{s}$ on glassy carbon electrode; arrows indicate scan direction. d, Schematic of cell in discharge mode. Grey arrow indicate flow direction of electrons and white arrows indicate electrolyte solution flow. Blue arrow indicates migration of cations across the membrane. Essential components of electrochemical cells are labeled with color-coded lines and text. 

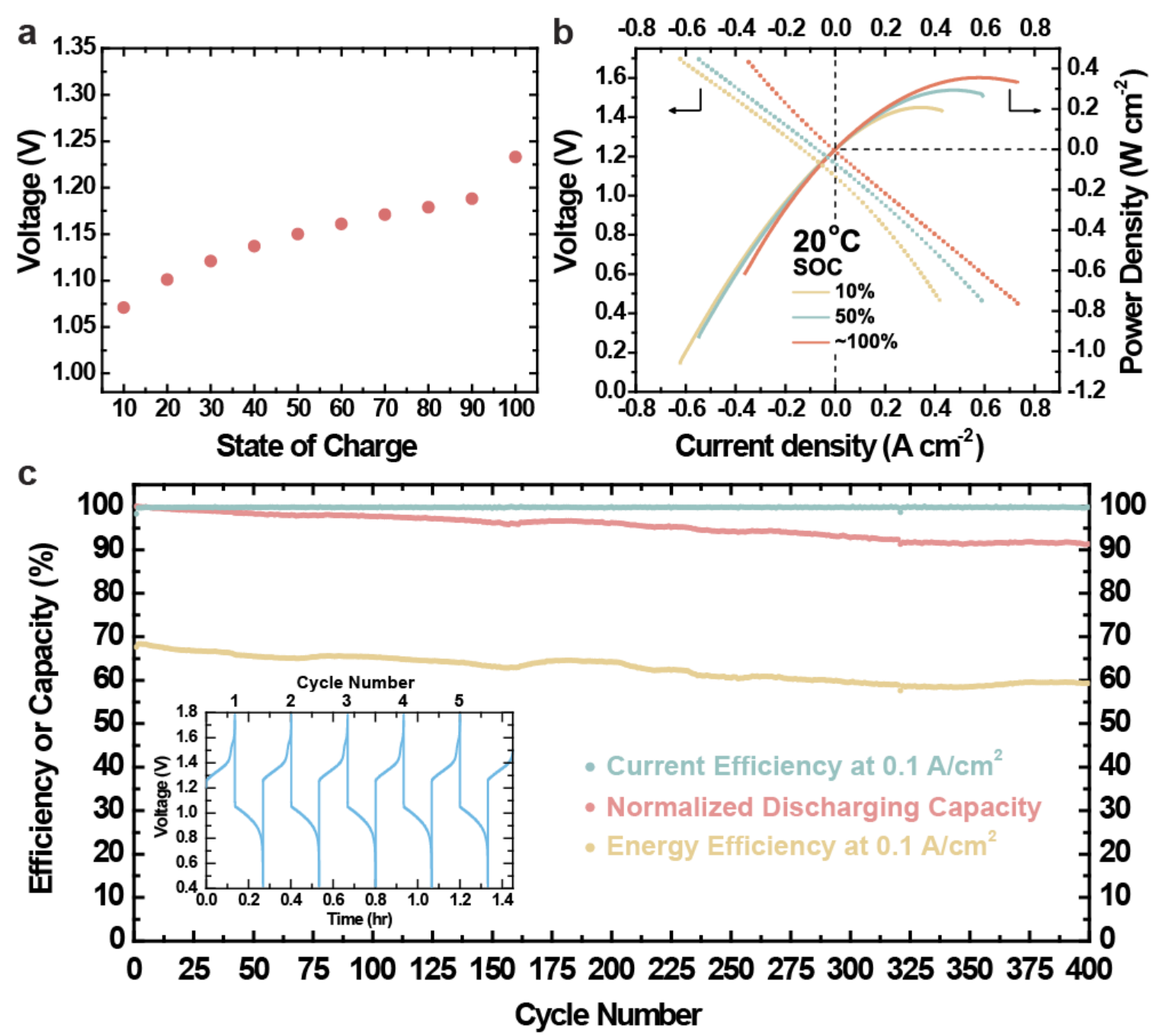

391
Figure 2 | Cell Performance (a) Cell open-circuit voltage (OCV) vs. state-of-charge (SOC). All potentials were taken when the cell voltage stabilized to within $\pm 1 \mathrm{mV} .100 \%$ SOC was reached by a potentiostatic hold at $1.5 \mathrm{~V}$ until the current decreased to below $5 \mathrm{~mA} / \mathrm{cm}^{2}$. (b) Cell voltage \& power density vs. current density at $20{ }^{\circ} \mathrm{C}$, at $10 \%, 50 \%$, and $100 \%$ SOC. Electrolyte composition: $0.5 \mathrm{M}$ ACA and $0.4 \mathrm{M}$ ferrocyanide $+40 \mathrm{mM}$ ferricyanide were used in negative electrolyte and positive electrolyte, respectively. (c) Capacity retention, current efficiency and energy efficiency values over 400 cycles at 0.1 $\mathrm{A} / \mathrm{cm}^{2}$. The normalized discharging capacity is evaluated based on the capacity of the first discharge cycle. (Inset: Representative voltage vs. time curves during 400 chargedischarge cycles at $0.1 \mathrm{~A} / \mathrm{cm}^{2}$, recorded between the $1^{\text {st }}$ and $5^{\text {th }}$ cycles.) 
a

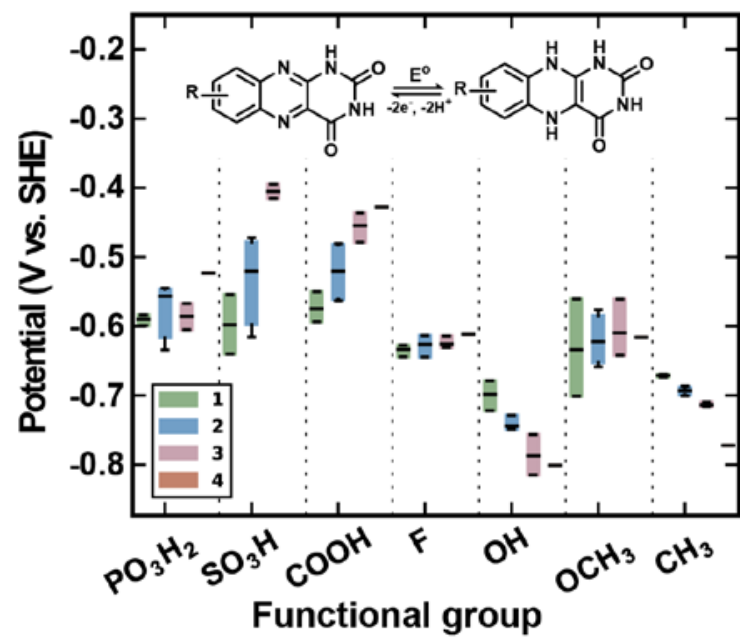

C

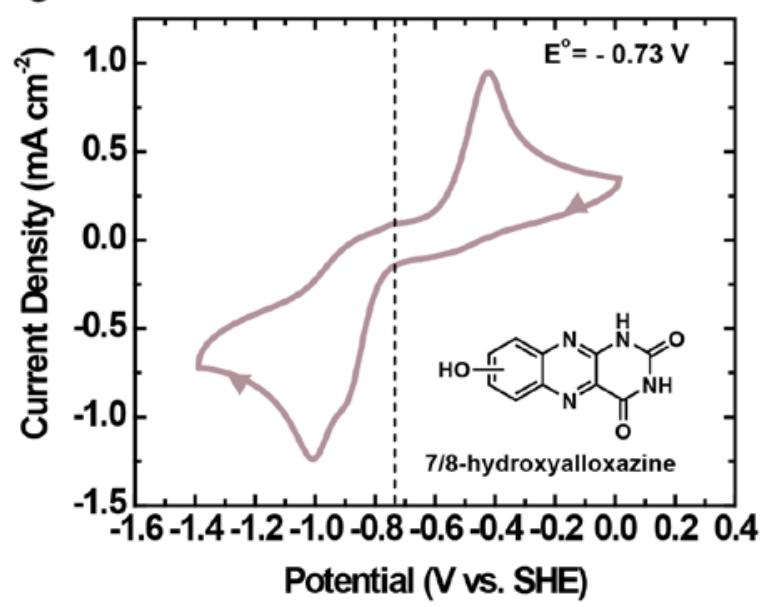

b
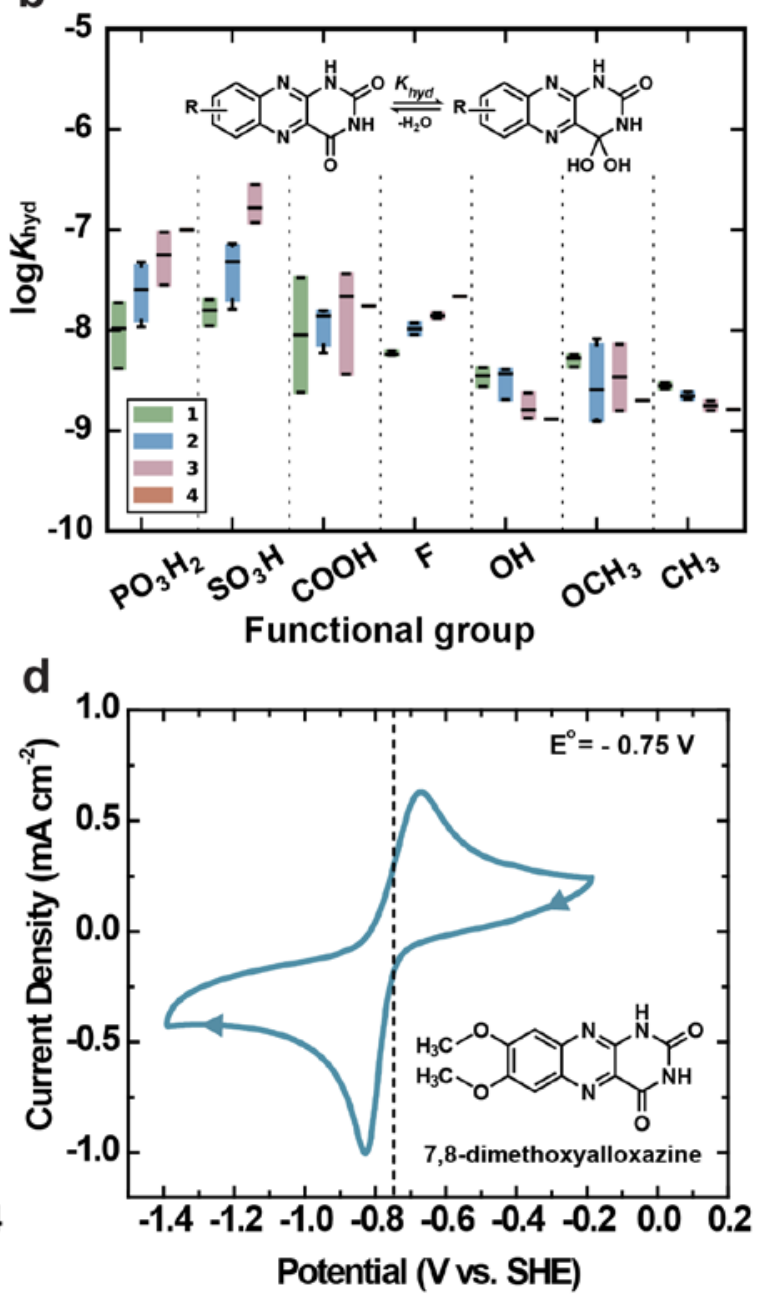

403

404

405

406

407

408

409

410

411

412

413

414

415

416

Figure 3 | Theoretical Calculation and Cyclic Voltammetry of alloxazines. (a)

Predicted reduction potential at the B3LYP 6-311+G** CPCM level of theory for substituted alloxazines at $\mathrm{pH}=14.0 \mathrm{vs}$. $\mathrm{RHE}$ as a function of number and type of substituent. (b) Predicted $\log K_{\text {hyd }}$ at the B3LYP 6-311+G** CPCM level of theory for substituted alloxazines as a function of number and type of substituent. The bars represent the statistical distribution of predictions of all the possible substituted molecules with the given number of substituted sites. The bottom and top of the bar are the first and third quartiles, and the band inside the box is the median. The lines extending vertically from the boxes indicate the maximum and minimum of the range. (c) and (d) Molecular structures and cyclic voltammogram of $1 \mathrm{mM}$ 7/8-hydroxyalloxazine and 7,8-dimethoxyalloxazine, respectively, scanned at $100 \mathrm{mV} / \mathrm{s}$ on glassy carbon electrode. 
417 Table 1 | High Performance Organic-based Aqueous Redox Flow Batteries. This

418 table focuses primarily on comparing molecular structures of redox-active organic

419 molecules and evaluating their electrochemical stability based on capacity retention.

\begin{tabular}{|c|c|c|c|c|c|c|c|}
\hline Positive Electrolyte & Negative Electrolyte & $\begin{array}{c}\text { No. of } \\
\text { Cycles } \\
\text { (Condition) }\end{array}$ & $\begin{array}{c}\text { Capacity } \\
\text { Retention per } \\
\text { Cycle }(\%)^{\mathrm{a}}\end{array}$ & $\begin{array}{l}\text { Energy } \\
\text { Density } \\
(\mathrm{Wh} / \mathrm{L})\end{array}$ & $\begin{array}{l}\text { Voltage } \\
\text { (V) }\end{array}$ & $\begin{array}{c}\text { Year of } \\
\text { Publication }\end{array}$ & $\begin{array}{c}\text { Merit } \\
\text { (limitation) }\end{array}$ \\
\hline \multirow{2}{*}{$\begin{array}{c}\text { bromine/ } \\
\text { hydrobromic acid }\end{array}$} & $\mathrm{HO}_{3} \mathrm{~S}$ & 10 & 99 & 16 & \multirow{2}{*}{0.86} & $2014^{8}$ & \multirow{2}{*}{$\begin{array}{l}\text { Low cost and } \\
\text { high } \\
\text { performance } \\
\text { (toxic } \\
\text { bromine) }\end{array}$} \\
\hline & $\begin{array}{l}\text { anthraquinone-2,7- } \\
\text { disulfonic acid }\end{array}$ & 750 & 99.84 & 16 & & $2014^{9}$ & \\
\hline ferrocyanide & $\begin{array}{l}\text { 2,6-dihydroxy- } \\
\text { anthraquinone }\end{array}$ & 100 & 99.1 & 6.8 & 1.2 & $2015^{10}$ & $\begin{array}{c}\text { Non-toxic and } \\
\text { less corrosive } \\
\text { electrolyte } \\
\text { (reduced ion } \\
\text { conductivity } \\
\text { w.r.t. proton) }\end{array}$ \\
\hline TEMPO polymer & viologen polymer & $\begin{array}{l}10,000 \\
\text { (non-flow } \\
\text { cell) }\end{array}$ & $\sim 99.75^{\mathrm{b}}$ & 10 & 1.15 & $2015^{11}$ & $\begin{array}{l}\text { Cheap dialysis } \\
\text { membrane } \\
\text { (high } \\
\text { electrolyte } \\
\text { viscosity) }\end{array}$ \\
\hline 4-hydroxy-TEMPO & methyl viologen & $\begin{array}{c}100 \text { (low } \\
\text { conc.) } \\
100 \text { (high } \\
\text { conc.) }\end{array}$ & $>99.99$ & 8.4 & 1.25 & $2015^{13}$ & $\begin{array}{l}\text { Low cost all- } \\
\text { organic } \\
\text { electrolyte } \\
\text { (low current } \\
\text { density) }\end{array}$ \\
\hline $\begin{array}{ll}420 & { }^{\mathrm{a}} \text { Capa } \\
421 & \text { discha } \\
422 & { }^{\mathrm{b}} \text { The } \\
423 & \text { figure }\end{array}$ & $\begin{array}{l}\text { y retention per cycle w } \\
\text { e cycles. } \\
\text { acity retention value w } \\
\text { from reference } 11 \text {. }\end{array}$ & $\begin{array}{l}\text { derived from } \\
\text { estimated bas }\end{array}$ & $\begin{array}{l}\text { otal capacity ret } \\
\text { d on the capacity }\end{array}$ & $\begin{array}{l}\text { ion divi } \\
\text { tention }\end{array}$ & $\begin{array}{l}\text { by total } \\
\text { ycle nur }\end{array}$ & $\begin{array}{l}\text { mber of cha } \\
\text { er graph in }\end{array}$ & \\
\hline
\end{tabular}


424 Table 2 | Reaction Scheme and Summary of Alloxazine Synthesis from Literature.

425 Alloxazines with different functional groups (-R) can be prepared by coupling 0 -

426 phenylenediamine derivatives with alloxane in the presence of acetic acid and boric acid.

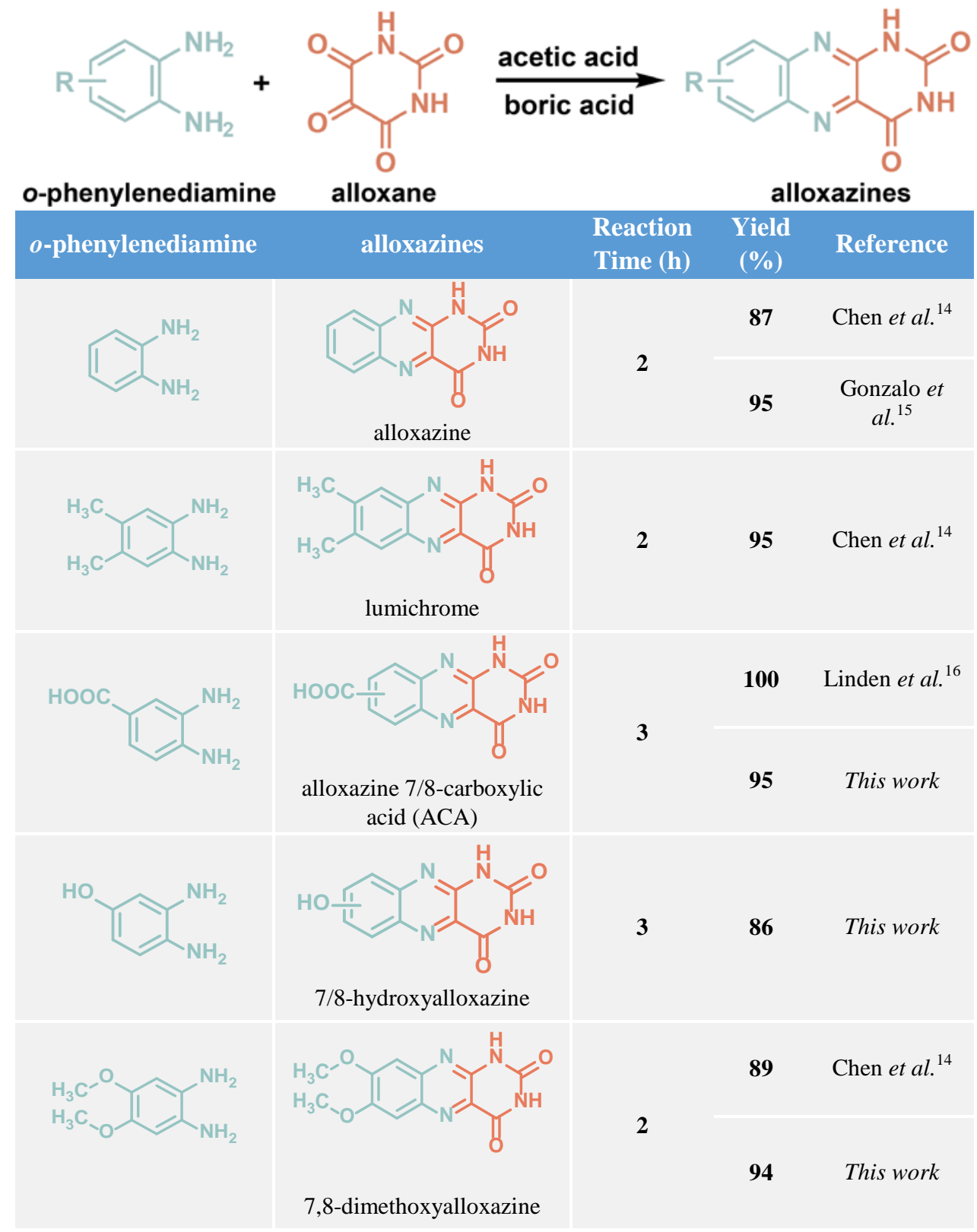


428 Table 3 | Theoretical Calculation and Substitution Patterns of Alloxazines. Predicted 429 standard reduction potential $\left(\mathrm{E}^{\circ}\right)$ and logarithmic hydration equilibrium constant $\left(\log K_{\mathrm{hyd}}\right)$ 430 for alloxazines with hydroxyl functional group(s).

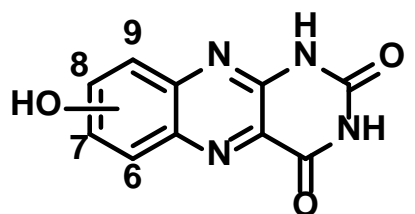

hydroxylated alloxazines

\begin{tabular}{|c|c|c|c|c|c|c|}
\hline \multirow{2}{*}{ No. } & \multicolumn{4}{|c|}{ Position (-OH) } & \multicolumn{2}{|c|}{ B3LYP 6-311+G** CPCM } \\
\hline & 6 & 7 & 8 & 9 & $E^{0}(V)$ & $\log K_{\text {hyd }}$ \\
\hline \multicolumn{7}{|c|}{1 Substituent } \\
\hline 1 & $\mathrm{H}$ & $\mathrm{H}$ & $\mathrm{H}$ & $-\mathrm{OH}$ & -0.69 & -8.4 \\
\hline 2 & $\mathrm{H}$ & $\mathrm{H}$ & $-\mathrm{OH}$ & $\mathrm{H}$ & -0.72 & -8.7 \\
\hline 3 & $\mathrm{H}$ & $-\mathrm{OH}$ & $\mathrm{H}$ & $\mathrm{H}$ & -0.68 & -8.5 \\
\hline 4 & $-\mathrm{OH}$ & $\mathrm{H}$ & $\mathrm{H}$ & $\mathrm{H}$ & -0.77 & -8.3 \\
\hline \multicolumn{7}{|c|}{2 Substituents } \\
\hline 5 & $-\mathrm{OH}$ & $-\mathrm{OH}$ & $\mathrm{H}$ & $\mathrm{H}$ & -0.75 & -8.4 \\
\hline 6 & $-\mathrm{OH}$ & $\mathrm{H}$ & $-\mathrm{OH}$ & $\mathrm{H}$ & -0.71 & -8.6 \\
\hline 7 & $-\mathrm{OH}$ & $\mathrm{H}$ & $\mathrm{H}$ & $-\mathrm{OH}$ & -0.77 & -8.2 \\
\hline 8 & $\mathrm{H}$ & $-\mathrm{OH}$ & $-\mathrm{OH}$ & $\mathrm{H}$ & -0.76 & -9.3 \\
\hline 9 & $\mathrm{H}$ & $-\mathrm{OH}$ & $\mathrm{H}$ & $-\mathrm{OH}$ & -0.68 & -8.4 \\
\hline 10 & $\mathrm{H}$ & $\mathrm{H}$ & $-\mathrm{OH}$ & $-\mathrm{OH}$ & -0.73 & -8.7 \\
\hline \multicolumn{7}{|c|}{3 Substituents } \\
\hline 11 & $-\mathrm{OH}$ & $-\mathrm{OH}$ & $-\mathrm{OH}$ & $\mathrm{H}$ & -0.81 & -8.9 \\
\hline 12 & $-\mathrm{OH}$ & $-\mathrm{OH}$ & $\mathrm{H}$ & $-\mathrm{OH}$ & -0.74 & -8.3 \\
\hline 13 & $-\mathrm{OH}$ & $\mathrm{H}$ & $-\mathrm{OH}$ & $-\mathrm{OH}$ & -0.82 & -8.7 \\
\hline 14 & $\mathrm{H}$ & $-\mathrm{OH}$ & $-\mathrm{OH}$ & $-\mathrm{OH}$ & -0.74 & -8.9 \\
\hline \multicolumn{7}{|c|}{4 Substituents } \\
\hline 15 & $-\mathrm{OH}$ & $-\mathrm{OH}$ & $-\mathrm{OH}$ & $-\mathrm{OH}$ & -0.80 & -8.9 \\
\hline
\end{tabular}




\section{A redox flow battery with an alloxazine-based organic electrolyte}

Kaixiang Lin ${ }^{1}$, Rafael Gómez-Bombarelli ${ }^{1}$, Eugene S. Beh ${ }^{1,2}$, Liuchuan Tong ${ }^{1}$, Qing Chen $^{2}$, Alvaro Valle ${ }^{3}$, Alán Aspuru-Guzik ${ }^{1}$, Roy G. Gordon ${ }^{1,2 *}$, Michael J. Aziz ${ }^{2 *}$

${ }^{1}$ Department of Chemistry and Chemical Biology, Harvard University, 12 Oxford Street, Cambridge, Massachusetts 02138, USA.

${ }^{2}$ Harvard John A. Paulson School of Engineering and Applied Sciences, 29 Oxford Street, Cambridge, Massachusetts 02138, USA.

${ }^{3}$ Harvard College, Cambridge, Massachusetts 02138, USA

*Correspondence to: RGG (gordon@chemistry.harvard.edu) and MJA

(aziz@seas.harvard.edu)

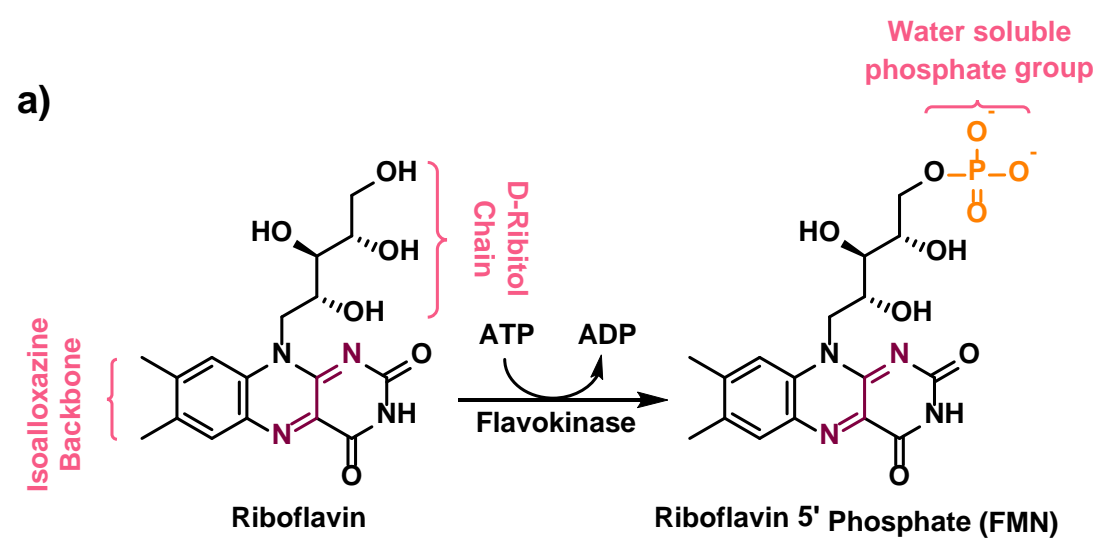

b)

Riboflavin 5' Phosphate

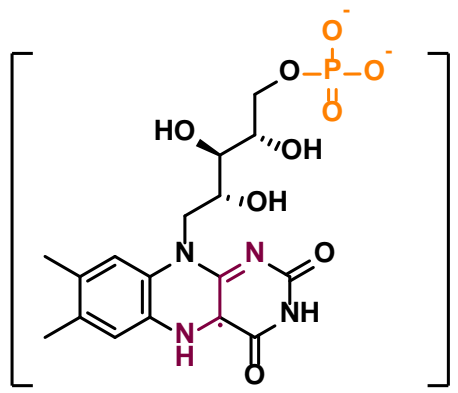

Flavin Semiquinone<smiles>Cc1cc2c(cc1C)N(C[C@H](O)[C@H](O)COP(=O)([O-])[O-])c1[nH]c(=O)[nH]c(=O)c1N2</smiles>

Hydroflavin

Supplementary Figure 1. (a) Biosynthesis of riboflavin 5' phosphate (FMN) from riboflavin (vitamin $B_{2}$ ). (b) Stepwise reduction of FMN into hydroflavin. ${ }^{18}$ 
a)

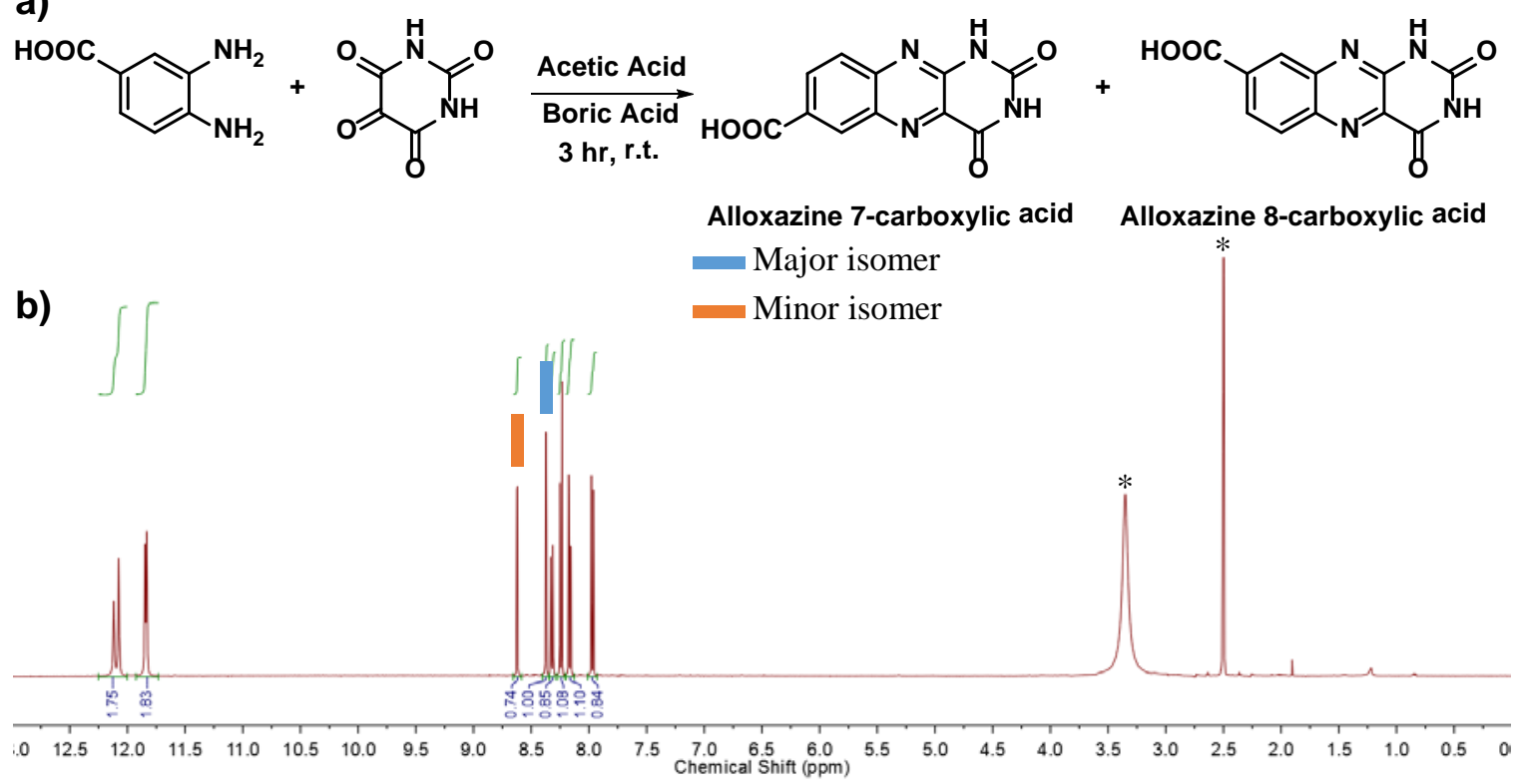

Supplementary Figure 2. (a) Synthetic scheme of alloxazine 7/8-carboxylic acid. (b) ${ }^{1} \mathrm{H}$ NMR (500 MHz, DMSO- $\mathrm{d}_{6}$ ) spectrum of alloxazine 7/8-carboxylic acid. Major isomer: $\delta$ 12.02 (s, 1H), 11.79 (s, 1H), 8.29 (d, $J=1.9 \mathrm{~Hz}, 1 \mathrm{H}), 8.18$ (d, $J=8.8 \mathrm{~Hz}, 1 \mathrm{H}), 8.09$ (dd, $J$ $=1.9,8.8 \mathrm{~Hz}, 1 \mathrm{H})$. Minor isomer: $\delta 12.06(\mathrm{~s}, 1 \mathrm{H}), 11.80(\mathrm{~s}, 1 \mathrm{H}), 8.55(\mathrm{~d}, J=2.0 \mathrm{~Hz}, 1 \mathrm{H})$, 8.25 (dd, $J=2.0,8.8 \mathrm{~Hz}, 1 \mathrm{H}$ ), 7.90 (d, $J=8.8 \mathrm{~Hz}, 1 \mathrm{H}$ ). Solvent peaks are labeled with asterisks. Final yield: 95\%. 

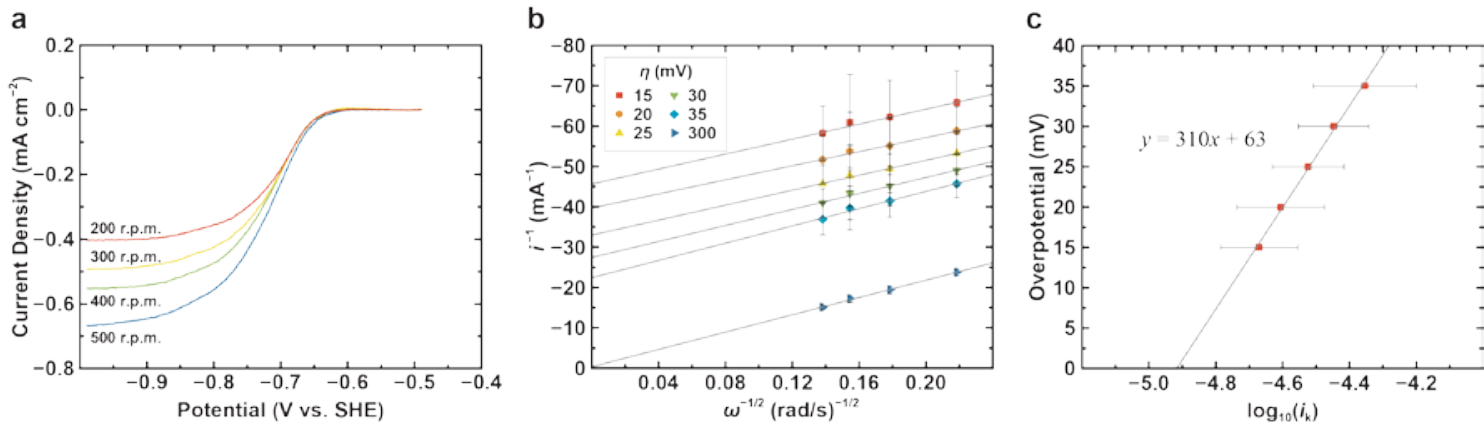

Supplementary Figure 3. (a) Plot of potential versus current density at different rotation rates of the RDE. The solution is $2 \mathrm{mM}$ ACA in $1 \mathrm{M}$ aqueous $\mathrm{KOH}$, using a rotating disk electrode (RDE) of glassy carbon. Rotation rates are indicated. (b) Koutecký-Levich plot $\left(i^{-1}\right.$ versus $\left.\omega^{-1 / 2}\right)$ of $2 \mathrm{mM}$ ACA in $1 \mathrm{M}$ aqueous $\mathrm{KOH}$. The current response, $i^{-1}$, is shown for six different ACA reduction overpotentials $\eta$. (c) Fit of RDE experimental data to the Tafel equation constructed using the current response in the absence of mass transport limitations at low ACA reduction potentials; $i_{\mathrm{k}}$ is the current extrapolated from the zero-intercept of the fitted lines in (b) (i.e. at infinite rotation rate). The line of best fit has the equation $y=310 x+63$, from which $\alpha=0.47(4)$ and $k_{0}=1.2(2) \times 10^{-5} \mathrm{~cm} \mathrm{~s}^{-1}$ were calculated. Data are averaged over three runs; the numbers reported in parentheses indicate the standard deviation in the last reported digit. 

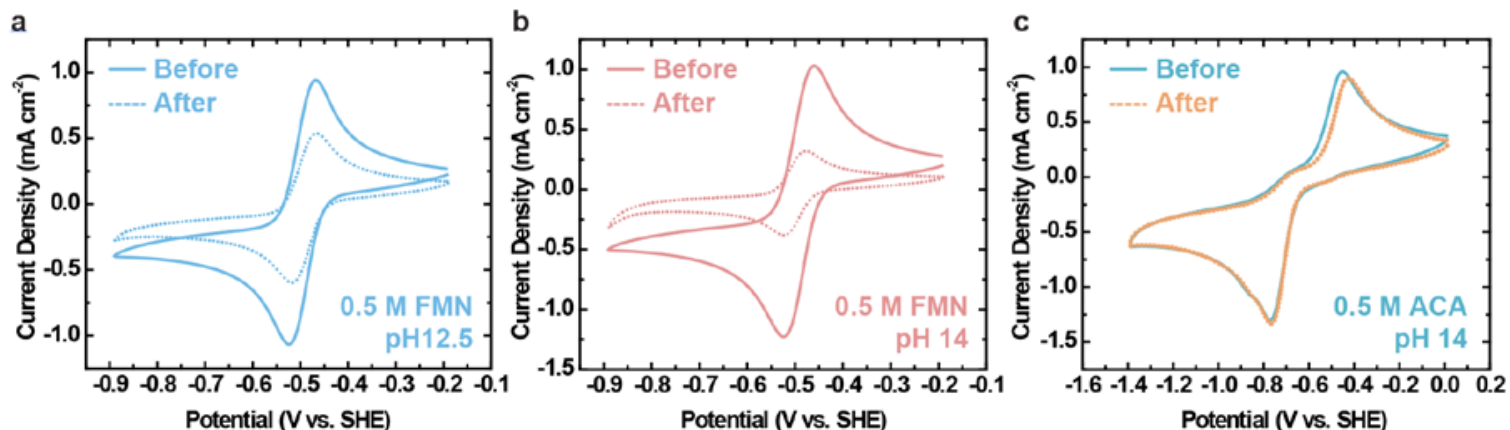

Supplementary Figure 4. (a) Cyclic voltammogram of $1 / 1000^{\text {th }}$ dilution of riboflavin 5 , phosphate (FMN) at $\mathrm{pH} 12.5$ before (solid line) and after (dotted line) 14 days, scanned at $100 \mathrm{mV} / \mathrm{s}$ on a glassy carbon electrode. (b) and (c) Cyclic voltammogram of $1 / 1000^{\text {th }}$ dilution of riboflavin 5' phosphate (FMN) and alloxazine 7/8-carboxylic acid (ACA), respectively, at $\mathrm{pH} 14$ before (solid line) and after (dotted line) 14 days, scanned at 100 $\mathrm{mV} / \mathrm{s}$ on a glassy carbon electrode. 

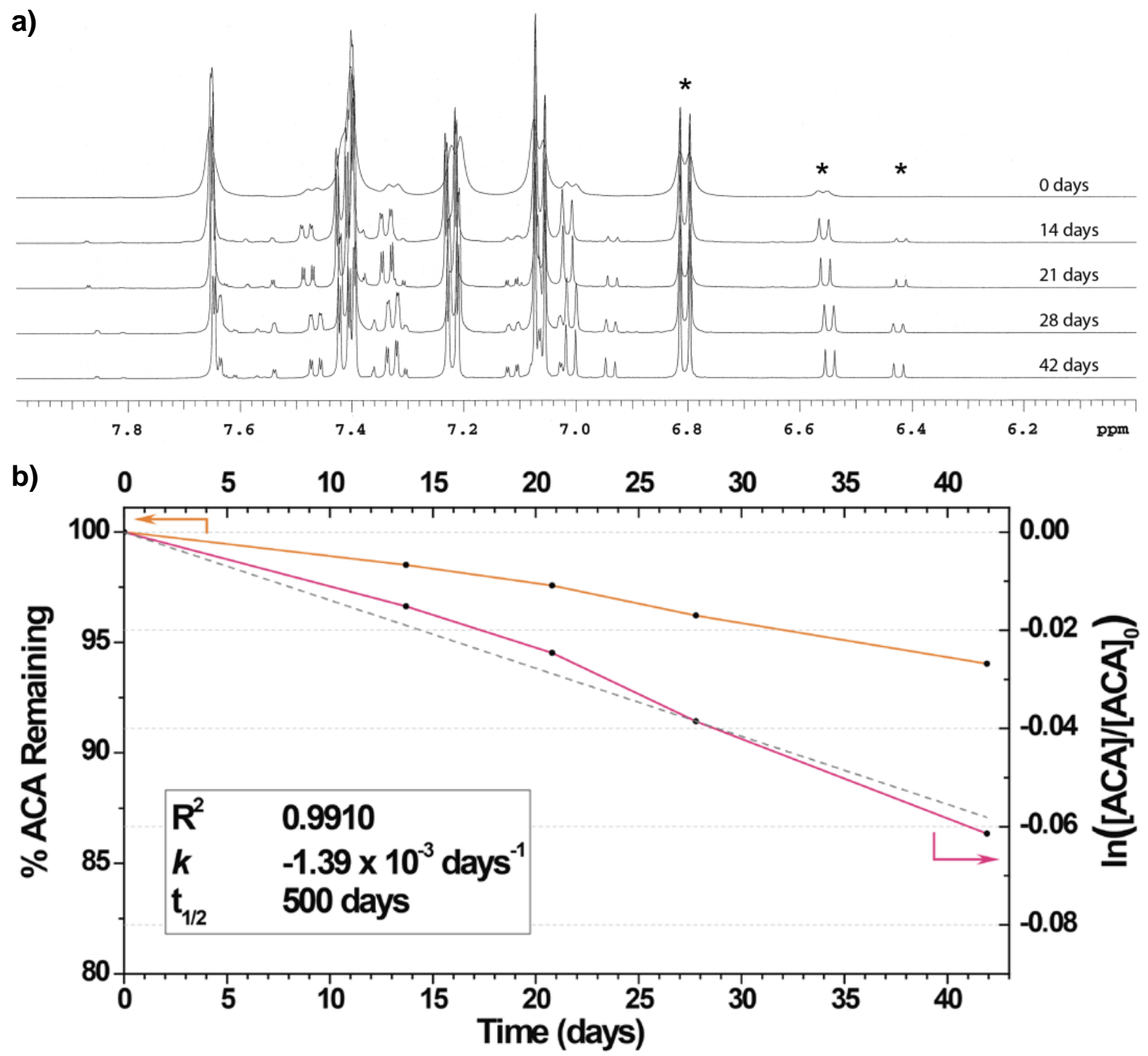

Supplementary Figure 5. ${ }^{1} \mathrm{H}$ NMR study of ACA stability in solution. (a) ${ }^{1} \mathrm{H}$ NMR spectra of a sample of $0.5 \mathrm{M}$ ACA at $\mathrm{pH} 14$ after various time points. The proportion of ACA that had decomposed was determined by comparing the area of the doublet that emerges at $6.43 \mathrm{ppm}$ to the sum of the areas of the doublets at $6.55 \mathrm{ppm}$ and $6.81 \mathrm{ppm}$, which come from the starting material. The peaks of interest are marked with a star. (b) Graphical depiction of the percentage of ACA remaining in the sample as a function of time (orange trace, left axis), as well as the same data replotted assuming first-order kinetics (pink trace, right axis). The gray dashed line represents the least-squares linear fit to the data in the pink trace. 


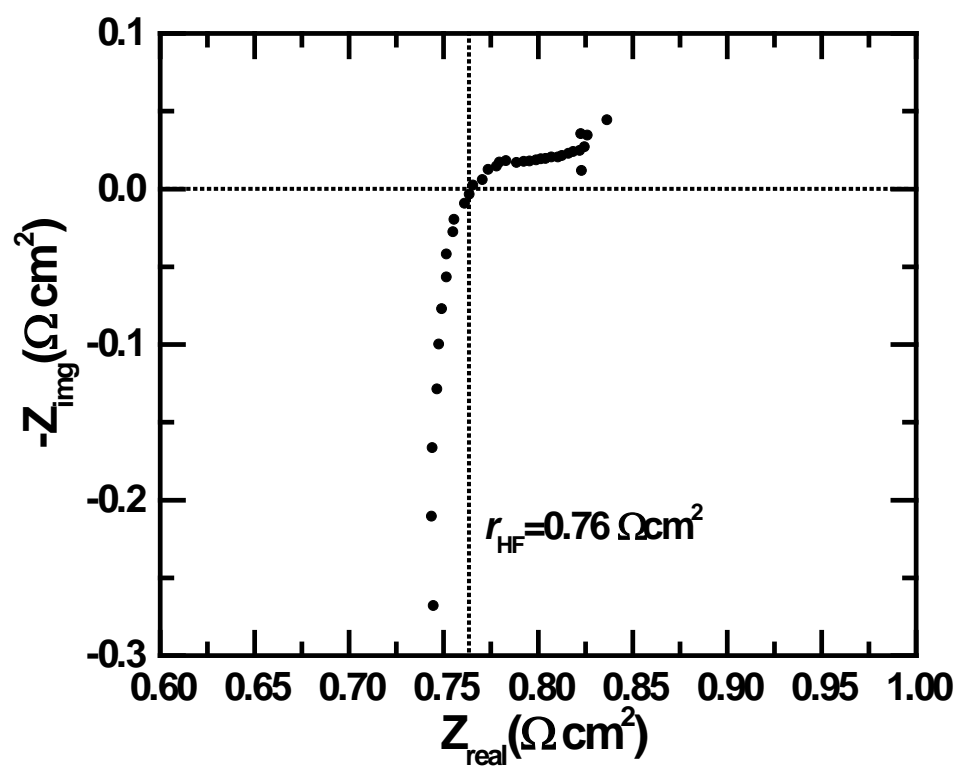

Supplementary Figure 6. Electrochemical impedance spectroscopy (EIS) of the ACAferrocyanide cell discussed in Fig. 3a and $\mathbf{3 b}$. The EIS data were captured at 50\% SOC. A high-frequency ASR $\left(r_{\mathrm{HF}}\right)$ was taken at $\sim 80 \mathrm{kHz}$ to be $0.76 \Omega \mathrm{cm}^{2}$. This comprises the membrane ionic resistance, the electrode electronic resistances, and the contact resistances, but not the electrolyte resistances. As the sum of the cell contact resistance and the electrode electronic resistance was previously measured in a dry-cell (a setup identical to the flow cell, but without the membrane and the flowing electrolyte) to be $\sim 0.02 \Omega \mathrm{cm}^{2}$, the membrane resistance, by subtraction, is thus $\sim 0.74 \Omega \mathrm{cm}^{2}$. 


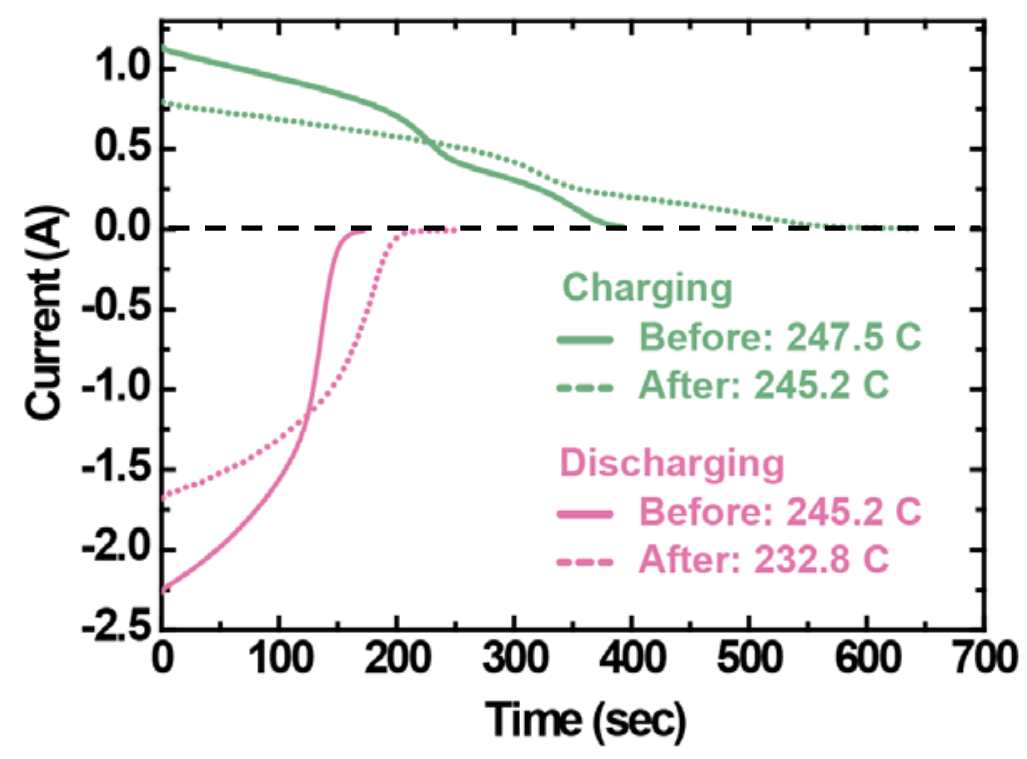

Supplementary Figure 7. Chronoamperometric (constant voltage) charging and discharging of ACA before (solid line) and after (dotted line) the 400 cyclic chargedischarge study. Black dashed line indicates zero current. Integration of the curves gives a 95\% discharge capacity retention after 400 cycles.

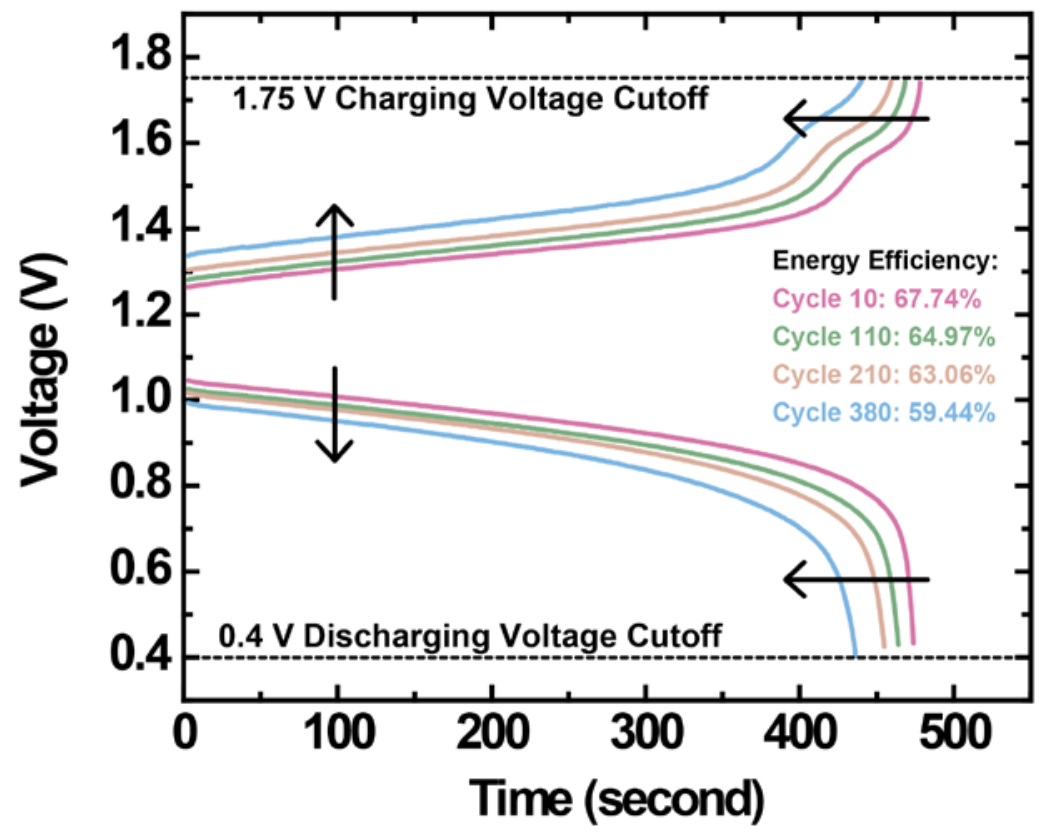

Supplementary Figure 8. Charging and discharge profiles of ACA at cycle no. 10, 110, 210 and 380 in the 400-cycle charge-discharge study. Black dashed lines indicate the voltage cutoffs. Black arrows represent the shifting directions of the curves during the course of the cycling study. 

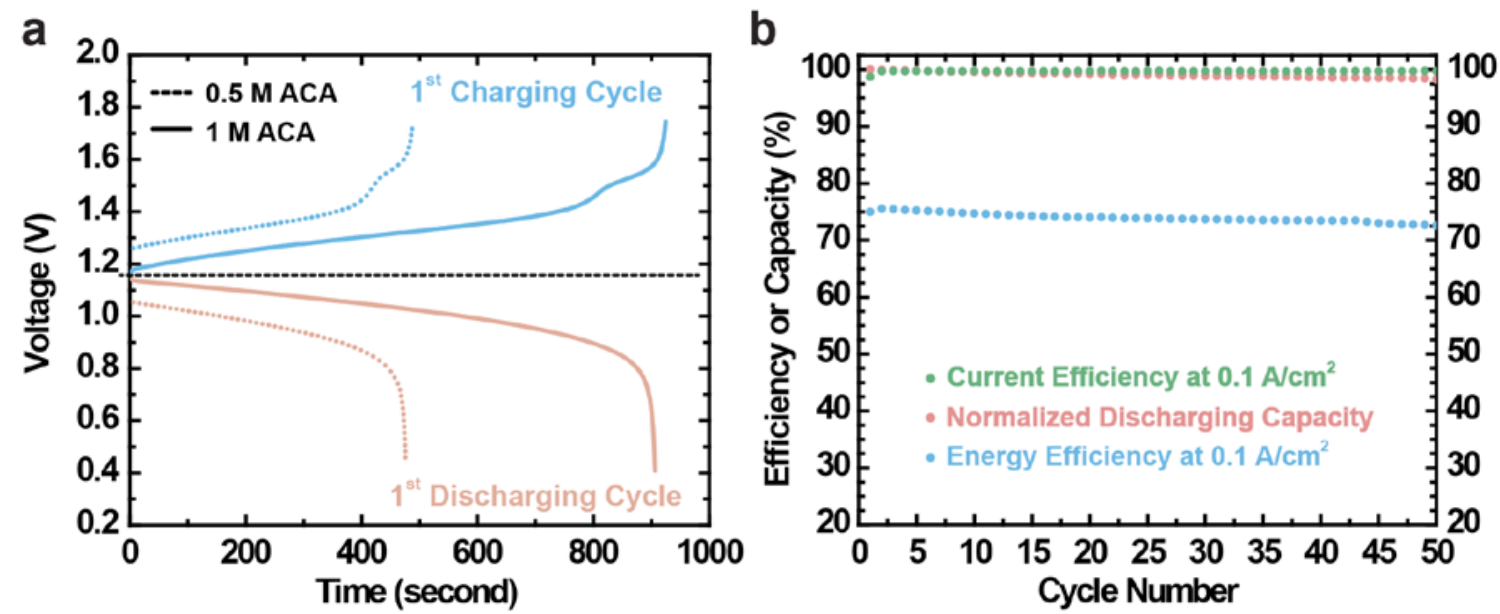

Supplementary Figure 9. (a) Representative voltage vs. time curves of the $1^{\text {st }}$ chargedischarge cycle at $0.1 \mathrm{~A} / \mathrm{cm}^{2}$ for $0.5 \mathrm{M}$ ACA (dotted line) and $1 \mathrm{M}$ ACA (solid line) vs. $0.4 \mathrm{M}$ ferrocyanide $+40 \mathrm{mM}$ ferricyanide. (b) Capacity retention (97.5\%), current efficiency (99.7\%) and energy efficiency (74\%) values measured over 50 chargedischarge cycles of the $1 \mathrm{M}$ ACA negative electrolyte at $0.1 \mathrm{~A} / \mathrm{cm}^{2}$. Normalized discharging capacity is evaluated based on the capacity of the first discharge cycle. 
a)

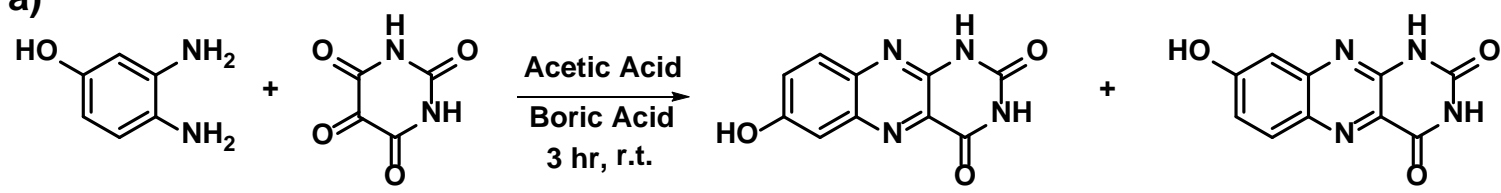

7-hydroxyalloxazine

b)

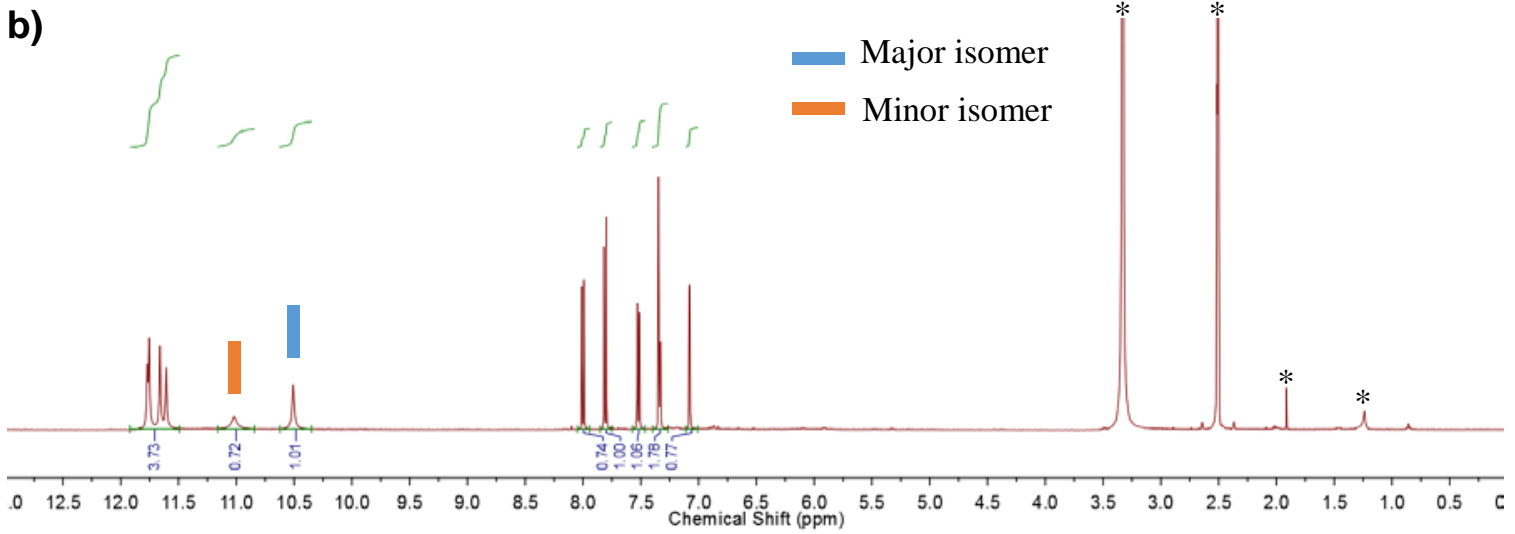

Supplementary Figure 10. (a) Synthetic scheme for 7/8-hydroxyalloxazine. (b) ${ }^{1} \mathrm{H}$ NMR (500 MHz, DMSO-d ${ }_{6}$ ) spectrum of 7/8-hydroxyalloxazine. Major isomer: $\delta 12.02$ (s, 1H), 11.79 (s, 1H), 8.29 (d, $J=1.9 \mathrm{~Hz}, 1 \mathrm{H}), 8.18$ (d, $J=8.8 \mathrm{~Hz}, 1 \mathrm{H}$ ), 8.09 (dd, $J=1.9$, $8.8 \mathrm{~Hz}, 1 \mathrm{H})$. Minor isomer: $\delta 12.06(\mathrm{~s}, 1 \mathrm{H}), 11.80(\mathrm{~s}, 1 \mathrm{H}), 8.55(\mathrm{~d}, J=2.0 \mathrm{~Hz}, 1 \mathrm{H}), 8.25$ (dd, $J=2.0,8.8 \mathrm{~Hz}, 1 \mathrm{H}), 7.90$ (d, $J=8.8 \mathrm{~Hz}, 1 \mathrm{H}$ ). Solvent peaks are labeled with asterisks. Final yield: $86 \%$.

a)<smiles>COc1cc(N)c(N)cc1OC</smiles><smiles>O=C1NC(=O)C(=O)N1</smiles>

Acetic Acid Boric Acid $3 \mathrm{hr}$, r.t.<smiles>COc1cc2nc3[nH]c(=O)[nH]c(=O)c3nc2cc1OC</smiles>

b)

\section{7,8-dimethoxyalloxazine}

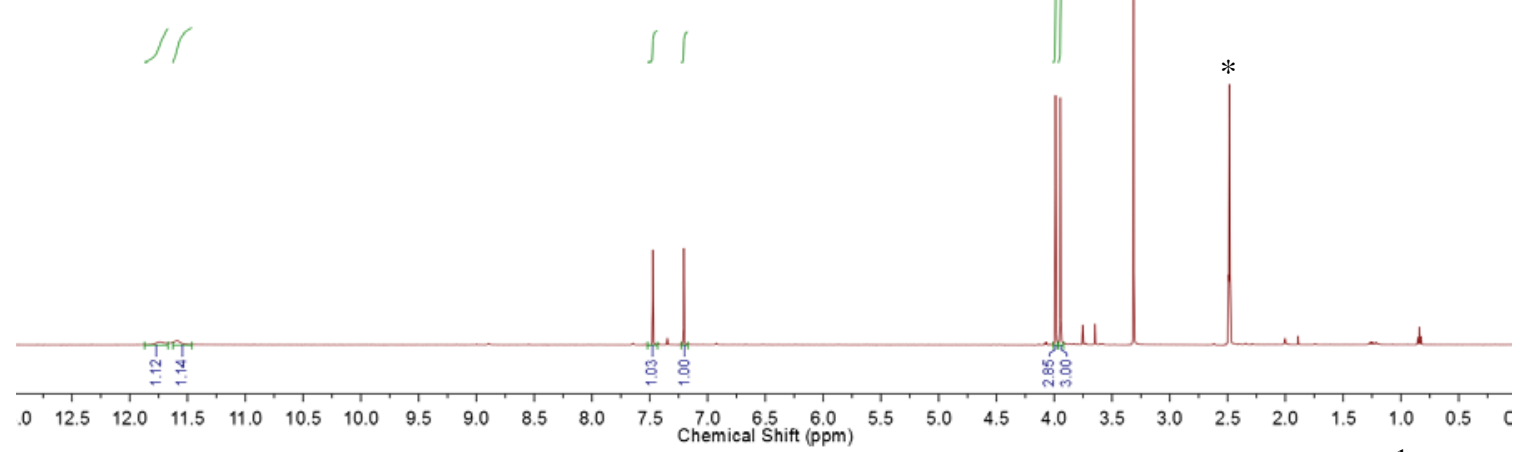

Supplementary Figure 11. (a) Synthetic scheme of 7,8-dimethoxyalloxazine. (b) ${ }^{1} \mathrm{H}$ NMR (500 MHz, DMSO-d ${ }_{6}$ ) spectrum of 7,8-dimethoxyalloxazine $\delta 12.02(\mathrm{~s}, 1 \mathrm{H}), 11.79$ (s, 1H), 8.29 (d, $J=1.9 \mathrm{~Hz}, 1 \mathrm{H}), 8.18$ (d, $J=8.8 \mathrm{~Hz}, 1 \mathrm{H}), 8.09$ (dd, $J=1.9,8.8 \mathrm{~Hz}, 1 \mathrm{H})$. Solvent peaks are labeled with asterisks. Final yield: $94 \%$. 


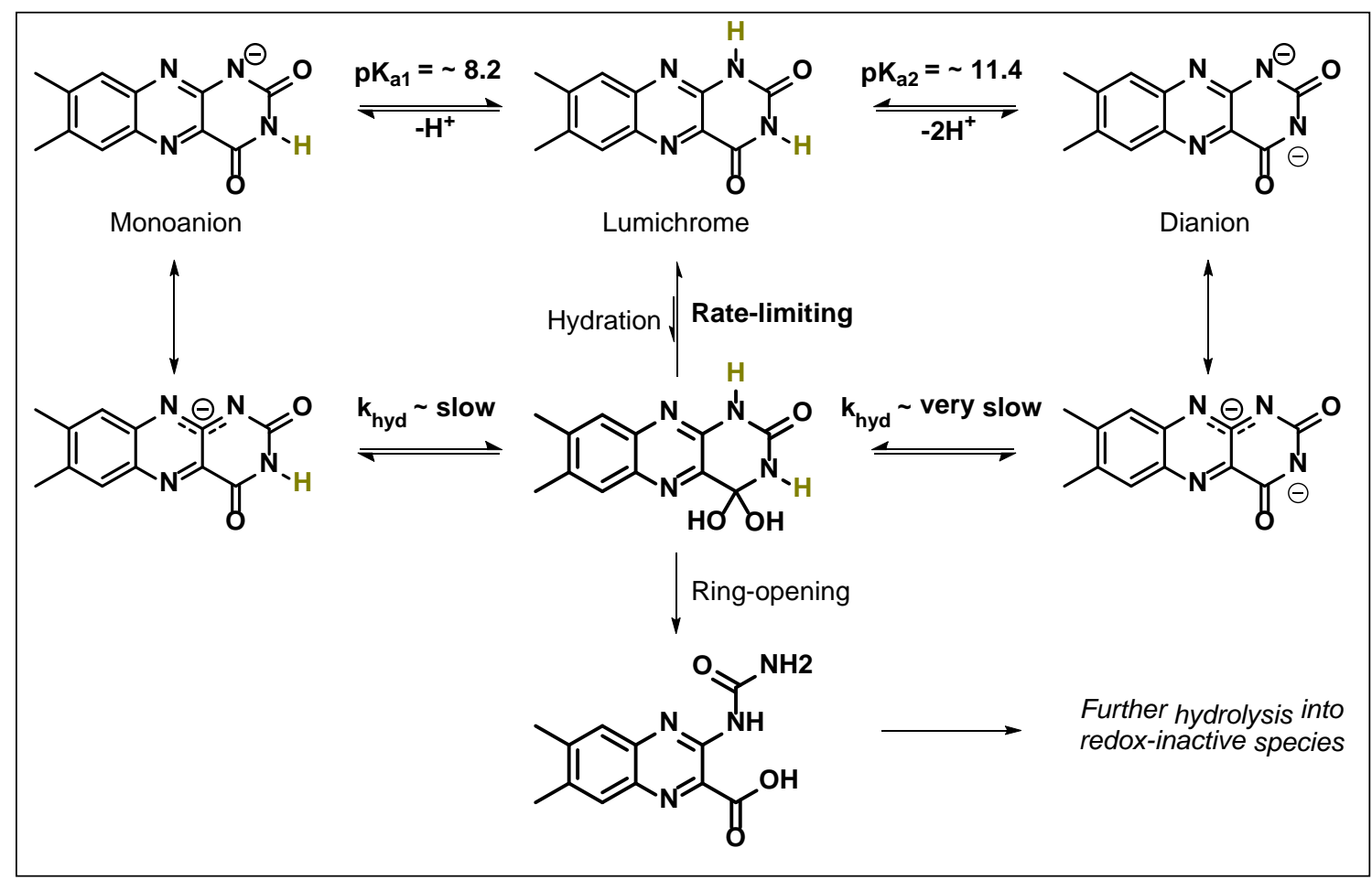

Supplementary Figure 12. Deprotonation, hydration and ring-opening reactions of lumichrome (7,8-dimethylalloxazine). ${ }^{20}$ 

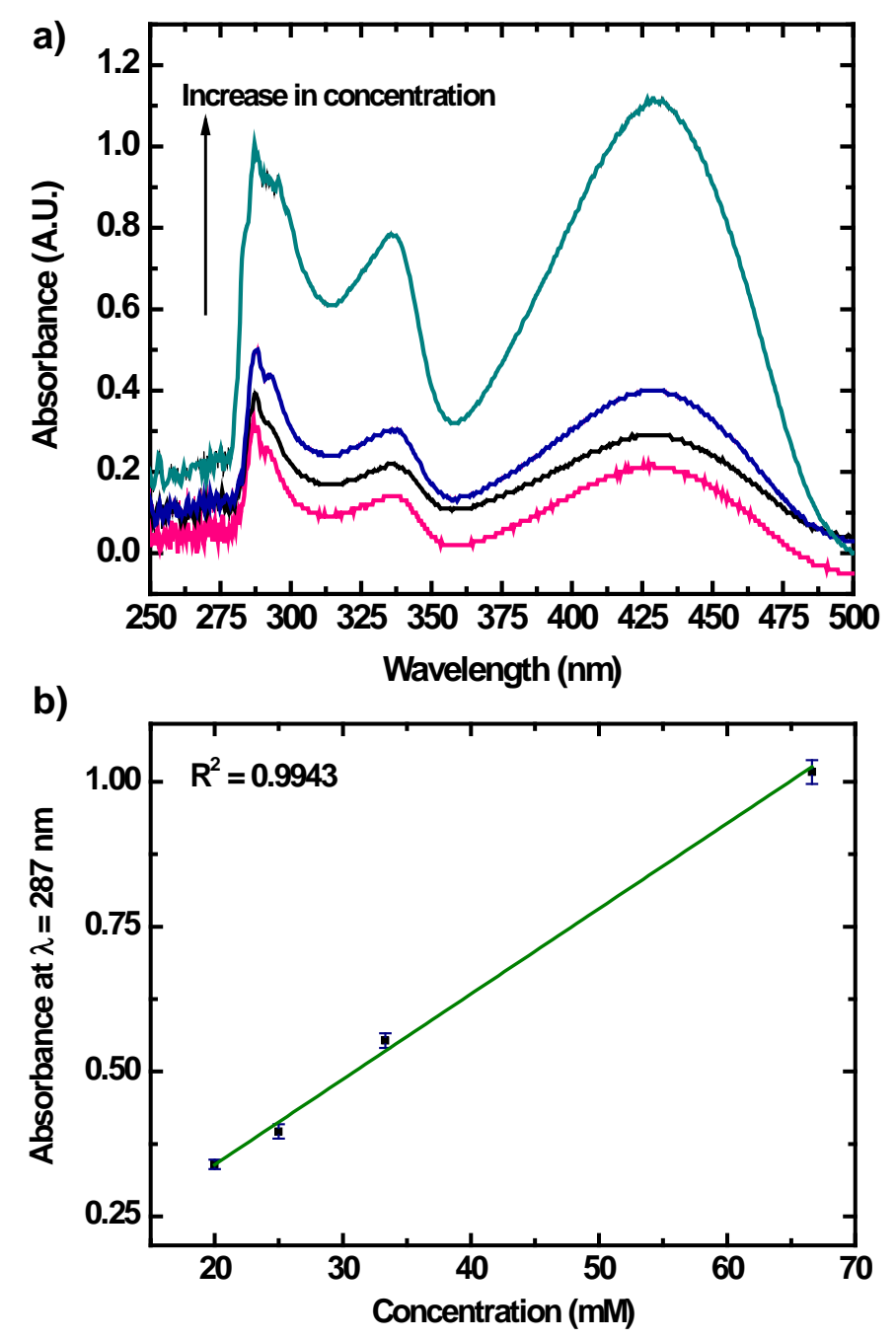

Supplementary Figure 13. (a) UV-Vis spectra of ACA at different concentration. (b) Standard calibration curve of ACA absorbance at $\lambda=287 \mathrm{~nm}$ vs. concentration. This calibration curve was interpolated to determine the concentration of ACA in diluted aliquots of a saturated solution, from which the saturation concentration of ACA was calculated. 
Supplementary Table 1. Substitution patterns and predicted standard reduction potential $\left(E^{0}\right)$ and logarithmic hydration equilibrium constant $\left(\log K_{\text {hyd }}\right)$ for alloxazines.

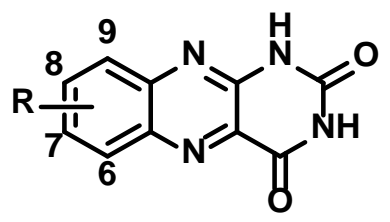

alloxazine derivatives

\begin{tabular}{|c|c|c|c|c|c|c|c|c|c|c|c|c|c|c|c|}
\hline \multicolumn{4}{|c|}{ Position } & \multicolumn{12}{|c|}{ B3LYP 6-311+G** CPCM } \\
\hline 6 & 7 & 8 & 9 & $\mathbf{E}^{0}(\mathbf{V})$ & $\overline{\log K_{\text {hyd }}}$ & $\mathrm{E}^{0}(\mathrm{~V})$ & $\overline{\log K_{\text {hyd }}}$ & $\mathrm{E}^{\mathbf{0}}(\mathrm{V})$ & $\overline{\log K_{\text {hyd }}}$ & $\mathbf{E}^{0}(\mathbf{V})$ & $\overline{\log K_{\text {hyd }}}$ & $E^{0}(V)$ & $\overline{\log K_{\text {hyd }}}$ & $E^{0}(V)$ & $\log K_{\text {hyd }}$ \\
\hline \multicolumn{4}{|c|}{1 substituent } & \multicolumn{2}{|c|}{$\mathrm{R}=-\mathrm{PO}_{3} \mathrm{H}_{2}$} & \multicolumn{2}{|c|}{$\mathrm{R}=-\mathrm{SO}_{3} \mathrm{H}$} & \multicolumn{2}{|c|}{$\mathrm{R}=-\mathrm{COOH}$} & \multicolumn{2}{|c|}{$\mathrm{R}=-\mathrm{F}$} & \multicolumn{2}{|c|}{$\mathrm{R}=-\mathrm{OCH}_{3}$} & \multicolumn{2}{|c|}{$\mathrm{R}=-\mathrm{CH}_{3}$} \\
\hline $\mathbf{H}$ & $\mathrm{H}$ & $\mathrm{H}$ & $\mathrm{R}$ & -0.62 & -9.4 & -0.67 & -7.7 & -0.53 & -6.1 & -0.63 & -8.1 & -0.54 & -8.3 & -0.67 & -8.5 \\
\hline $\mathbf{H}$ & $\mathrm{H}$ & $\mathrm{R}$ & $\mathrm{H}$ & -0.57 & -8.0 & -0.52 & -7.9 & -0.56 & -7.9 & -0.66 & -8.2 & -0.71 & -8.2 & -0.68 & -8.6 \\
\hline $\mathbf{H}$ & $\mathrm{R}$ & $\mathrm{H}$ & $\mathrm{H}$ & -0.59 & -7.2 & -0.57 & -7.7 & -0.60 & -8.2 & -0.64 & -8.3 & -0.70 & -8.6 & -0.67 & -8.6 \\
\hline $\mathrm{R}$ & $\mathrm{H}$ & $\mathrm{H}$ & $\mathrm{H}$ & -0.59 & -7.9 & -0.63 & -8.1 & -0.59 & -10.0 & -0.63 & -8.2 & -0.57 & -8.3 & -0.67 & -8.5 \\
\hline \multicolumn{16}{|c|}{2 substituents } \\
\hline $\mathrm{R}$ & $\mathrm{R}$ & $\mathrm{H}$ & $\mathrm{H}$ & -0.52 & -9.0 & -0.47 & -9.4 & -0.56 & -8.2 & -0.63 & -8.0 & -0.61 & -7.7 & -0.68 & -8.6 \\
\hline $\mathrm{R}$ & $\mathrm{H}$ & $\mathrm{R}$ & $\mathrm{H}$ & -0.64 & -7.7 & -0.54 & -7.8 & -0.49 & -10.4 & -0.64 & -8.1 & -0.63 & -8.9 & -0.70 & -8.8 \\
\hline $\mathrm{R}$ & $\mathrm{H}$ & $\mathrm{H}$ & $\mathrm{R}$ & -0.63 & -7.3 & -0.63 & -7.4 & -0.45 & -7.8 & -0.61 & -7.9 & -0.49 & -8.1 & -0.69 & -8.6 \\
\hline $\mathbf{H}$ & $\mathrm{R}$ & $\mathrm{R}$ & $\mathrm{H}$ & -0.55 & -7.3 & -0.50 & -7.2 & -0.57 & -7.9 & -0.65 & -8.0 & -0.76 & -8.3 & -0.70 & -8.7 \\
\hline H & $\mathrm{R}$ & $\mathrm{H}$ & $\mathrm{R}$ & -0.56 & -7.5 & -0.62 & -7.1 & -0.48 & -7.8 & -0.61 & -7.9 & -0.58 & -9.2 & -0.69 & -8.7 \\
\hline $\mathbf{H}$ & $\mathrm{H}$ & $\mathrm{R}$ & $\mathrm{R}$ & -0.55 & -8.0 & -0.47 & -7.0 & -0.56 & -7.7 & -0.62 & 7.9 & -0.66 & -8.9 & -0.69 & -8.6 \\
\hline \multicolumn{16}{|c|}{3 substituents } \\
\hline $\mathrm{R}$ & $\mathrm{R}$ & $\mathrm{R}$ & $\mathrm{H}$ & -0.60 & -7.4 & -0.41 & -6.9 & -0.44 & -7.9 & -0.63 & -7.9 & -0.64 & -8.1 & -0.71 & -8.6 \\
\hline $\mathrm{R}$ & $\mathrm{R}$ & $\mathrm{H}$ & $\mathrm{R}$ & -0.61 & -7.1 & -0.40 & -7.1 & -0.43 & -7.4 & -0.59 & -7.8 & -0.51 & -8.2 & -0.70 & -8.7 \\
\hline $\mathrm{R}$ & $\mathrm{H}$ & $\mathrm{R}$ & $\mathrm{R}$ & -0.57 & -8.2 & -0.38 & -6.1 & -0.47 & -10.1 & -0.62 & -7.8 & -0.58 & -8.8 & -0.71 & -8.9 \\
\hline $\mathbf{H}$ & $\mathrm{R}$ & $\mathrm{R}$ & $\mathrm{R}$ & -0.56 & -6.8 & -0.43 & -6.7 & -0.51 & -7.4 & -0.63 & -7.9 & -0.64 & -8.9 & -0.72 & -8.8 \\
\hline \multicolumn{16}{|c|}{4 substituents } \\
\hline $\mathrm{R}$ & $\mathrm{R}$ & $\mathrm{R}$ & $\mathrm{R}$ & -0.52 & -9.7 & -0.35 & -6.3 & -0.43 & -7.8 & -0.61 & -7.7 & -0.62 & -8.7 & -0.77 & -8.8 \\
\hline
\end{tabular}


Supplementary Table 2. Predicted error in standard reduction potential $\left(E^{0}\right)$ values for (iso)alloxazine molecules at $\mathrm{pH}=7.4$ and in logarithmic hydration equilibrium constant $\left(\log K_{\text {hyd }}\right)$ values.

\begin{tabular}{|c|c|c|c|c|}
\hline \multirow{2}{*}{ Method } & \multicolumn{2}{|c|}{$\boldsymbol{E}^{\mathbf{0}} \mathbf{( V )}$} & \multicolumn{2}{c|}{$\operatorname{logK}_{\text {hyd }}$} \\
\cline { 2 - 5 } & $\mathbf{R}^{\mathbf{2}}$ & Mean Error (meV) & $\mathbf{R}^{\mathbf{2}}$ & Mean Error (log units) \\
\hline PM7 & 0.86 & 23 & 0.79 & 1.5 \\
\hline PM7 COSMO & 0.90 & 24 & 0.88 & 1.3 \\
\hline PBE 6-31G* & 0.90 & 24 & 0.88 & 1.2 \\
\hline B3LYP 6-31G* & 0.87 & 27 & 0.89 & 1.1 \\
\hline B3LYP 6-311+G** & 0.89 & 25 & 0.85 & 1.2 \\
\hline B3LYP 6-311+G** CPCM & 0.97 & 8 & 0.90 & 1.0 \\
\hline
\end{tabular}

